WHC-EP-0695

\title{
Proof of Principle Report for In-Tank Moisture Monitoring Using an Active Neutron Probe
}

Prepared for the U.S. Department of Energy

$\checkmark$ Office of Environmental Restoration and Waste Management

\section{(W) Westinghouse \\ W. Hanford Company Richland, Washington}

Hanford Operations and Engineering Contractor for the

US Department of Energy under Contract DE ACOS 87RL.10930 


\section{LEGAL DISCLAIMER}

This report was prepared as an account of work sponsored by an agency of the United States Government. Neither the United States Government nor any agency thereot, nor any of their employees, nor any of their coniractors, subcontractors or their employees, makes any warranty, express or implied, or assumes any legal liability or responsibility for the accuracy, completeness, or any third party's use or the results of such use of any information, apparatus, product, or process disclosed. or represents that its use would not intringe privately owned rights. Reterence herein to any specific commercial product, process, or service by trade name trademark, manufacturer, or otherwise, does not necessarily constitute or imply its endorsement, recommendation, or favoring by the United States Government or any agency thereot or its contractors or subcontractors. The views and opinions of authors expressed herein do not necessarily state or reflect those of the United States Government or any agency thereot.

This report has been reproduced from the best available copy Available in paper copy and microfiche.

Available to the U.S. Department of Energy and its contractors from

Otfice of Scientific and Technical Information P.O. $80 \times 52$

Oak Ridge. TN 37831

(615) $576-8401$

Available to the public trom the U.S. Department of Commerce National Technical intormation Service

5285 Port Royal Road

Springtield, VA 22161

(703) $487-4650$

Printed in the United States of America 
WHC-EP-0695

\section{Proof of Principle Report for In-Tank Moisture Monitoring Using an Active Neutron Probe}

W. T. Watson

Date Published

December 1993

Prepared for the U.S. Department of Energy Office of Environmental Restoration and Waste Management 
This page intentionally left blank. 


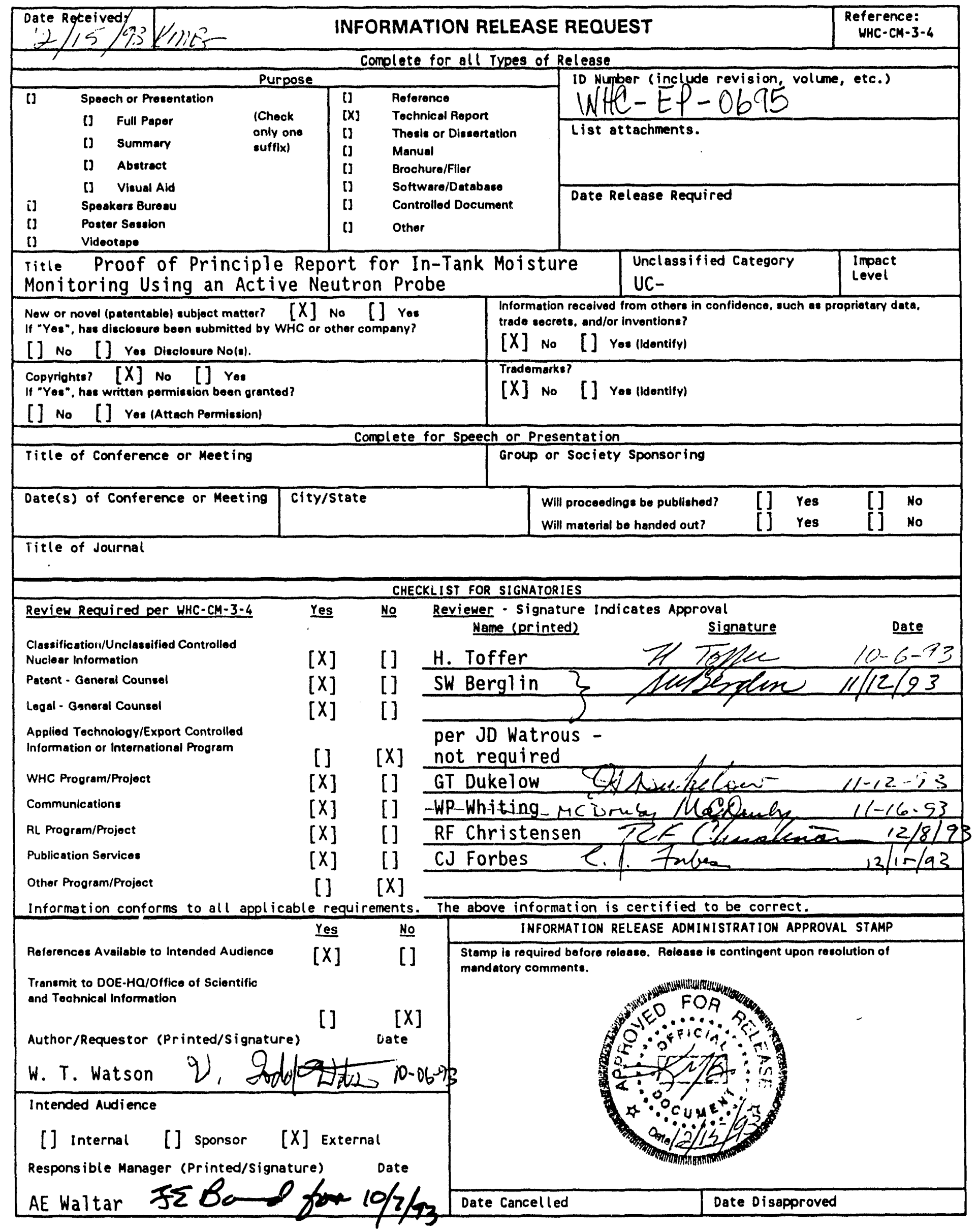


WHC-EP-0695

This page intentionally left blank 


\section{PROOF OF PRINCIPLE REPORT FOR IN-TANK MOISTURE MONITORING USING AN ACTIVE NEUTRON PROBE}

\section{EXECUTIVE SUMMARY}

This document establishes the proof of principle for use of a neutron probe to measure moisture concentrations in ferrocyanide waste tanks at the Hanford Site. Computer modeling and experiments with a modified neutron probe have shown that neutron-based measurements will provide accurate moisture determinations in Hanford Site ferrocyanide waste tanks. Moisture measurement using neutron moderation and diffusion is an established and extensively documented technology for the well logging industry. Sophisticated neutron transport modeling and calibrations with known moisture concentrations have provided the necessary developmental analyses and validations. Proof of principle was accomplished using the existing in-tank neutron surveillance tool and its support equipment. A minor, inexpensive hardware modification permitted extending the use of the existing probe to moisture measurements. A limited moisture calibration was performed using the modified in-tank neutron probe, and the results were used to adjust model parameters. Scan data from three ferrocyanide tanks have been obtained using the modified in-tank neutron probe, and interpretation of these scans is in progress. Modeling analyses and experimental test results have provided information that will be used to develop a prototype neutron device for improved in-tank moisture monitoring at the Hanford Site. Now a prototype device must be assembled, tested, and fully calibrated in known moisture ferrocyanide waste simulants. 
WHC-EP-0695

This page intentionally left blank. 
WHC-EP-0695

\section{CONTENTS}

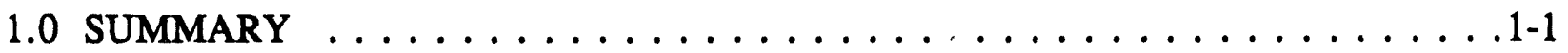

2.0 BACKGROUND . . . . . . . . . . . . . . . . . . . . 2-1

2.1 CURRENT NEUTRON PROBE TANK SURVEILLANCE $\ldots \ldots \ldots \ldots .2-1$

2.2 LITERATURE REVIEW $\ldots \ldots \ldots \ldots \ldots \ldots \ldots \ldots \ldots \ldots \ldots \ldots \ldots$

2.2.1 Moisture Gauge and Neutron $\log \ldots \ldots \ldots \ldots \ldots \ldots . \ldots \ldots 2-1$

2.2.2 Concerns About Measurements . . . . . . . . . . . . 2-2

2.2.3 Pulsed Neutron $\log \ldots \ldots \ldots \ldots \ldots \ldots \ldots . \ldots \ldots . . \ldots \ldots$

2.2.4 Monte Carlo Modeling . . . . . . . . . . . . 2-3

3.0 ASSESSMENT OF THE CURRENT NEUTRON PROBE FOR

MOISTURE MEASUREMENT . . . . . . . . . . . . . . . . 3-1

3.1 DESCRIPTION OF THE SOURCE-DETECTOR SYSTEM . . . . . . . . 3-1

3.2 COMPARISON OF MCNP MODEL PREDICTIONS

AND EXPERIMENTAL TEST DATA $\ldots \ldots \ldots \ldots \ldots \ldots$. . $\ldots \ldots$

4.0 INTERPRETATION OF TANK SCANS . . . . . . . . . . . . . . 4-1

4.1 INTERPRETATION OF SLUDGE REGION DETECTOR RESPONSES . . 4-2

4.2 INTERPRETATION OF THE SALTCAKE REGION DETECTOR

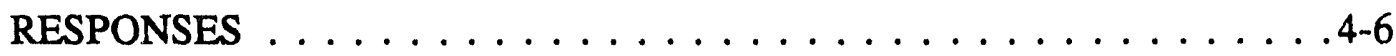

5.0 DESIGN RECOMMENDATIONS FOR AN IMPROVED MOISTURE MEASUREMENT NEUTRON PROBE $\ldots \ldots \ldots \ldots \ldots \ldots \ldots \ldots$. . . . . .

6.0 CONTINUING DEVELOPMENT AND INVESTIGATION $\ldots \ldots \ldots \ldots \ldots$. $\ldots \ldots$

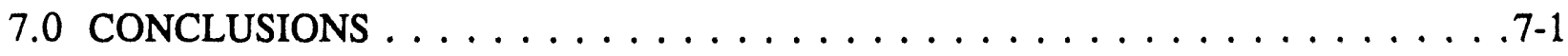

8.0 REFERENCES $\ldots \ldots \ldots \ldots \ldots \ldots \ldots \ldots \ldots \ldots \ldots . \ldots \ldots . \ldots \ldots$ 


\section{LIST OF FIGURES}

3-1 Sketch of Current In-Tank Neutron Probe Geometry . . . . . . . . . . . . 3-2

3-2 Geometry of Limited Moisture Standards

Containing an Aluminum Casing $\ldots \ldots \ldots \ldots \ldots \ldots \ldots \ldots$

3-3 Comparison of Measured Values and MCNP Modeled Detector

Responses with the Probe Immersed in Water $\ldots \ldots \ldots \ldots \ldots . \ldots . . \ldots$

3-4 Comparison of a Literature Neutron Source Spectrum with the MCNP

Modeled Spectrum Used to Obtain Best Agreement

with Measured Data . . . . . . . . . . . . . . . . . . . . 3-5

3-5 Comparison of Measured Values and MCNP Modeled Detector

Responses with the Probe Inside an LOW Immersed in Water $\ldots . . . . .36$

3-6 Comparison of Measured Values and MCNP Modeled Detector

Responses with the Probe Deployed in Moisture Standards . . . . . . . . . 3-6

3-7 Comparison of Measured Values and MCNP Modeled Detector

Responses with the Probe Deployed in Moisture Standards $\ldots \ldots \ldots$. . . . 3-8

3-8 Comparison of Measured Values and MCNP Modeled Detector Responses for Two Source-to-Detector Separations . . . . . . . . . . . . 3-8

3-9 Comparison of Measured and MCNP Modeled Response Ratios for Two Source-to-Detector Separations . . . . . . . . . . . . . . . . . . 3-9

4-1 MCNP Predicted Near-Field Detector Response to Sludge with 10 Weight Percent Borosilicate LOW Content $\ldots \ldots \ldots \ldots$. . . . 4-1

4-2 MCNP Predicted Far-Field Detector Response to Sludge with 10 Weight Percent Borosilicate LOW Content . . . . . . . . . . . 4-3

4-3 Calculated Near- to Far-Field Ratio Sludge Moisture Calibration Curve . . . . . . . . . . . . . . . . . . . . 4-3

4-4 Tank 241-BY-107 Neutron Scans and Near- to-Far-Field Response Ratio . . . . . . . . . . . . . . . . . . . . 4-5

4-5 Tank 241-BY-111 Neutron Scans and Near- to Far-Field Response Ratio . . . . . . . . . . . . . . . . . . . . .4-7 


\section{LIST OF FIGURES (continued)}

4-6 Tank 241-BY-110 Neutron Scans and Near- to Far-Field Response Ratio . . . . . . . . . . . . . . . . . . . . . 4-8

4-7 In-Tank Photograph of LOW and its Entrance into the Saltcake of Tank 241-BY-107 . . . . . . . . . . . . . . . . . . 4-9

4-8 Calculated Near- and Far-Field Responses to Annular Air Holes Between LOW and Saltcake . . . . . . . . . . . . . . . . . . . 4-11

4-9 Comparison of Calculated Responses of an Epithermal

Detector to Different Moisture Concentration Sludge for Two LOW Borosilicate Concentrations . . . . . . . . . . . . . . . . . . . . . 4-12

\section{LIST OF TABLES}

4-1 Modeled Predicted Probe Count Rates Compared with Measured Count Rates in the Riser/Soil Region . . . . . . . . . . . . . . . . 4-2 
WHC-EP-U695

This page intentionally left blank. 


\section{PROOF OF PRINCIPLE REPORT FOR IN-TANK MOISTURE MONITORING USING AN ACTIVE NEUTRON PROBE}

\subsection{SUMMARY}

Moisture measurement using neutron diffusion is an established technology that uses a neutron source and one or more neutron detectors. The thermal or epithermal neutrons reaching a detector originate as fast neutrons from the source and are slowed or absorbed by the medium. Because hydrogen atoms are the most effective at slowing neutrons, the detector response is a strong function of the surrounding moisture concentration.

The Monte Carlo Neutron Photon (MCNP) mathematical neutron transport modeling code has been used to predict the responses of neutron devices to changes in intrinsic device design or in surrounding conditions, such as moisture concentration (LANL 1986). A neutron probe currently monitors the interstitial liquid level in some waste tanks. Small modifications, based upon model results, were implemented on the existing in-tank neutron probe to improve its use as a moisture measurement device. An assessment of the moisturemeasuring capabilities of this device constitutes the major portion of the proof of principle of an in-tank neutron diffusion-based moisture monitoring system.

A limited moisture calibration was performed using the modified in-tank neutron probe. The measurements were made with the probe under controlled conditions, and the results were used to adjust model parameters. Reasonable agreement between model predictions and measured results was obtained.

Scan data of three ferrocyanide tanks have been obtained using the modified in-tank neutron probe. Improved moisture measurements with reduced uncertainties may be achieved with more complete calibrations, an improved device design, and with longer data collection time. Interpretations of the scans relating the data to moisture concentrations is in progress.

Additional calibrations in more representative materials are needed for accurate interpretations to be obtained from available data.

Modeling and experimental test results have provided information to be used in developing a prototype neutron device for improved in-tank moisture monitoring at the Hanford Site. This prototype device will include more than a single detector and will use epithermal detectors to reduce the effects of strong thermal neutron absorbers in the surrounding media. The spacings between the source and the detectors will be optimized for the desired moisture concentration sensitivity and vertical resolution. 
This page intentionally left blank. 


\subsection{BACKGROUND}

\subsection{CURRENT NEUTRON PROBE TANK SURVEILLANCE}

For about 15 years, a neutron probe has been used at Hanford Site tank farms to determine the air/liquid or interstitial liquid interface level (height) in the tanks. This measurement has provided a means to monitor changes in the tank liquid level. A change in the level could indicate a tank leak. Equipment and procedures to measure and obtain pertinent data are in place. A neutron moisture concentration measurement probe will build on this background of established surveillance activity and integrate it with the extensively developed methodology used in well logging applications. The potential of using the current in-tank probe for moisture measurement has been assessed, and recommendations for further study and development have led to the current work (Crowe and Heer 1992).

\subsection{LITERATURE REVIEW}

Since the 1940's, significant study and work using neutron tools for measuring moisture concentrations in geophysical formations has been done. A large literature base describes the technique of using neutron diffusion to measure moisture. The primary difference between techniques discussed in this literature and those applicable to Hanford Site waste tanks is that waste tank techniques must operate effectively in a high gamma radiation environment, and they must account for material compositions and geometries that are tank-specific. Much of the literature information can be applied effectively to the assessment of an in-tank neutron diffusion-based moisture measurement technique.

\subsubsection{Moisture Gauge and Neutron Log}

The two primary neutron tools used in well logging for moisture measurement are the moisture gauge and the neutron log. An excellent review and comparison of the methods, applications, and sensitivities of these tools can be found in A Comparison of the Moisture Gauge and the Neutron Log in Air-filled Holes (Hearst and Carlson 1993). Both methods for the measurement of moisture concentration around wells are based upon neutron moderation and diffusion. The first method, the moisture gauge, has a short source-to-detector spacing, $0 \mathrm{~cm}$ to $6 \mathrm{~cm}$. At the shortest spacing $(0 \mathrm{~cm})$ the source is placed in a ring around the detector. The response of a moisture gauge is characterized by an increase in detector response with increasing moisture concentration of the surrounding medium. A thermal neutron detector is usually employed in the moisture gauge. The second method, the neutron $\log$, often has two detectors with longer source-to-detector spacing $(20$ to $50 \mathrm{~cm})$ that exhibit a decreased response to increased moisture concentrations. In a neutron $\log$, the detector placed at the shorter spacing is used to correct the response of the more distant detector for borehole effects. 
In general, the neutron log is more sensitive to low moisture concentrations (below about 15 weight percent), while the moisture gauge is more sensitive to high moisture concentrations (above about 25 weight percent). Because of its small vertical extent, the moisture gauge exhibits better vertical spacial resolution to changes in the surrounding media. The neutron log interrogates a larger vertical extent than the moisture gauge and a greater radial extent. Typically, the neutron $\log$ interrogates a radius of about $30 \mathrm{~cm}$, while the moisture gauge interrogates a radius of only about $18 \mathrm{~cm}$. These investigation distances vary with the density, moisture content, and neutron absorber content of the surrounding media.

\subsubsection{Concerns About Measurements}

The neutron log and the moisture gauge are affected by several characteristics of the surrounding media (other than moisture concentration). The primary material properties that may affect the tool's response are the density, the presence of hydrogen other than in water, and the presence of strong thermal neutron absorbers. The presence of liquid in the well hole, not encountered in Hanford Site liquid observation wells (LOW), would strongly affect the response of any neutron moisture measurement device.

Density variations in the surrounding media may change the apparent water content by about 10 volume percent per $1 \mathrm{~g} / \mathrm{cm}^{3}$ change in density (Hearst and Carlson 1993). Moisture measurements may be corrected for density effects if the density of the surrounding media is known. Density logging measurements are usually made using a gamma source and a detector arrangement that measures the number of photons that backscatter from and diffuse through the media to reach the detector(s) (Hearst and Nelson 1985). This method of determining the density of tank materials would be very difficult to implement in the $100 \mathrm{Rad} / \mathrm{h}$ gamma fields present in some Hanford Site waste tanks. Core sample analyses may provide useful density profile information about tank materials. The densities of tank waste materials from prior samples have shown variations in the density of sludge on the order of $0.5 \mathrm{~g} / \mathrm{cm}^{3}$. If the density of the waste is known to $\pm 0.25 \mathrm{~g} / \mathrm{cm}^{3}$, the effect of density uncertainty upon moisture concentration uncertainty will be smail.

The presence of hydrogen in materials other than water is not distinguishable from waterbound hydrogen. It is possible to make corrections to the moisture measurement by measuring this hydrogen content in samples or by using nuclear magnetic resonance techniques (McKague et al. 1992). Hydrogen is not expected to be present in significant quantity in most Hanford Site ferrocyanide tanks in any form other than water.

The effect of the presence of elements with a high thermal neutron absorption cross section may be virtually eliminated by using a device with an epithermal neutron detector (IAEA 1970). The presence of unknown and possibly varying concentrations of boron in the installed LOWs requires that the detector be relatively insensitive to changing concentrations of thermal neutron absorbers. Using an epithermal detector will decrease the detector counting rate, thereby increasing the statistical uncertainty of a measurement over another 
measurement obtained with a thermal detector using identical counting times. The use of epithermal detectors may also slightly decrease the sensitivity of the device to changing moisture concentrations. Compensation may be made by using stronger sources or longer counting times.

\subsubsection{Pulsed Neutron Log}

Often, a more accurate measure of the moisture concentration of the media may be obtained using pulsed source devices instead of steady-state tools. Using pulsed source tools allows a measurement technique that is more sensitive to changes in moisture content and less sensitive to the surrounding matrix material. The detector response can also be gated in time with respect to the pulse enabling separation of the borehole effects from the properties of the formation (Mills et al. 1991). A measure of the thermal neutron absorber content of the media sometimes can be made using a pulsed source system. Pulsed sources are also beneficial because of the reduced dose received by those working with them, and because they can be turned off. Pulsed source detector systems are much more complex and costly than steady-state source systems.

\subsubsection{Monte Carlo Modeling}

Neutron transport Monte Carlo codes are used to accurately predict the response of nuclear logging tools to various media, perturbations, and changes in tool design. Experiments show that Monte Carlo codes can predict absolute detector counting rates to varied but well-known materials to within an average of about 3 percent (Locke and Butler 1993). Real cost savings are possible using computer models of the device. Tests have demonstrated that calibration curves relating counting rates to moisture concentrations for a specific tool may be computed and require a relatively small number of confirming test measurements (Goncalves et al. 1992). With the availability of powerful computer workstations, many accurate calculations may be performed instead of costly experiments to investigate detector responses to changing conditions. 
This page intentionally left blank. 


\subsection{ASSESSMENT OF THE CURRENT NEUTRON PROBE FOR MOISTURE MEASUREMENT}

\subsection{DESCRIPTION OF THE SOURCE-DETECTOR SYSTEM}

The current in-tank neutron probe was developed to help determine the interstitial liquid level in the Hanford Site waste tanks. The probe consists of a $1.5 \mathrm{Ci} \mathrm{AmBe}$ neutron source and a single boron-trifluoride $\left(\mathrm{BF}_{3}\right)$ gas filled detector. The dimensions of the active region of the detector are $20.5 \mathrm{~cm}$ length and $3.8 \mathrm{~cm}$ diameter. The boron in the gas is enriched to 96 percent ${ }^{10} \mathrm{~B}$; the gas fill pressure in the detector is $25 \mathrm{~cm} \mathrm{Hg}$. The low fill pressure of the detector combined with relatively low sensitivity to photons allows the tube to operate in the high gamma fields $(100 \mathrm{Rad} / \mathrm{h})$ present in the waste tanks. The detector is also wrapped with $1.0 \mathrm{~cm}$-thick lead to provide additional gamma shielding. $\mathrm{BF}_{3}$ detectors are most sensitive to neutrons to thermal energy. The current detector, which is not covered with a thermal neutron absorber, is used as a thermal neutron detector. The source-detector arrangement is designed so that the spacing between the source and detector can be changed easily by connecting the source to the detector housing with a threaded spacer. With no spacer (source extender), the distance from the center of the source to the center of the detector active region is $18.3 \mathrm{~cm}$. The active detector region is $19.8 \mathrm{~cm}$ long and has a diameter of 3.37 $\mathrm{cm}$. A cross-sectional sketch of the detector deployed in a LOW (see Figure 3-1) identifies the basic geometry of the current probe. The probe accesses the tank contents from within a fiberglass LOW $7.62 \mathrm{~cm}$ ID to $8.89 \mathrm{~cm}$ outside diameter.

\subsection{COMPARISON OF MCNP MODEL PREDICTIONS AND EXPERIMENTAL TEST DATA}

MCNP (Version 3XE), a sophisticated radiation transport code, has been used to model the current neutron probe. This model allows the precise geometries, material compositions and densities, and source strength and spectrum to be specified in the input description. The code uses Monte Carlo techniques combines with a near-continuous energy treatment of neutron cross section data to determine the results of neutron interactions. Neutron importance-based geometry splitting with Russian Roulette is used as a variance reduction technique to increase the calculational efficiency of the modeled problems (Soran et al. 1990). The physics treatment of neutron interactions with hydrogen uses the $S(\alpha, \beta)$ method for interaction with water-bound hydrogen for neutron energies below about $4 \mathrm{eV}$. For higher incident neutron energies, a free gas model is employed in the calculation of scattering from hydrogen. 
Figure 3-1. Sketch of Current In-Tank Neutron Probe Geometry.

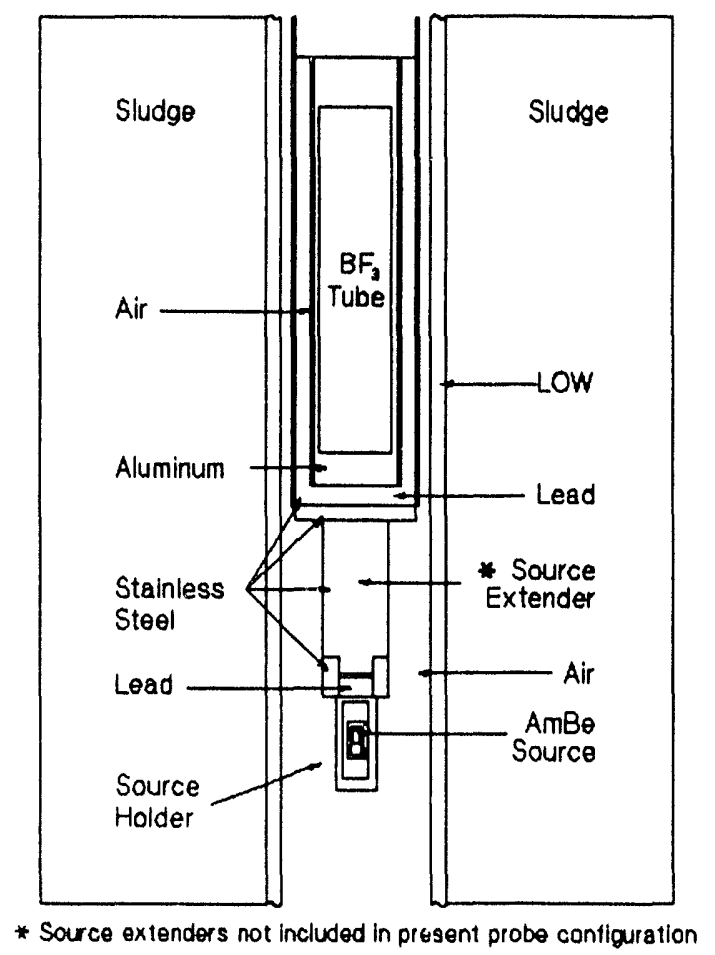

An initial calibration of the neutron probe for moisture concentration measurements was performed as part of the proof of principle effort. This calibration effort is limited in that it provides calibration curves for detector response (count rate) as a function of moisture concentration for a non-infinite media consisting of CLEAN UP IV* sorbent outside of aluminum and LOW casings. CLEAN UP IV is a sedimentary opal clay processed and used as a liquid sorbent. Information gained from measurements in the moisture standards allowed the Westinghouse Hanford Company (WHC) to adjust unknown MCNP model input parameters so the model may be applied to other similar media. Extended application of the model to significantly different conditions or media is possible, but it may require further model refinements. The extended application will require additional experimental validation.

On May 7, 1993, the measurements described below were taken in the moisture standards. Data were obtained for at least four source-to-detector spacings at several heights in each moisture standard. The standards consist of drums (314 L capacity) holding either water or a moisture sorbent containing a controlled moisture concentration (see Figure 3-2). The total moisture concentration of the sorbent is known only to about \pm 2 weight percent. Although the moisture content of the prepared sorbent drums was measured using a moisture analyzer,

\footnotetext{
*Trademark of Excel-Mineral Company, Inc., Goleta, California.
} 
Figure 3-2. Geometry of Limited Moisture Standards Containing an Aluminum Casing.

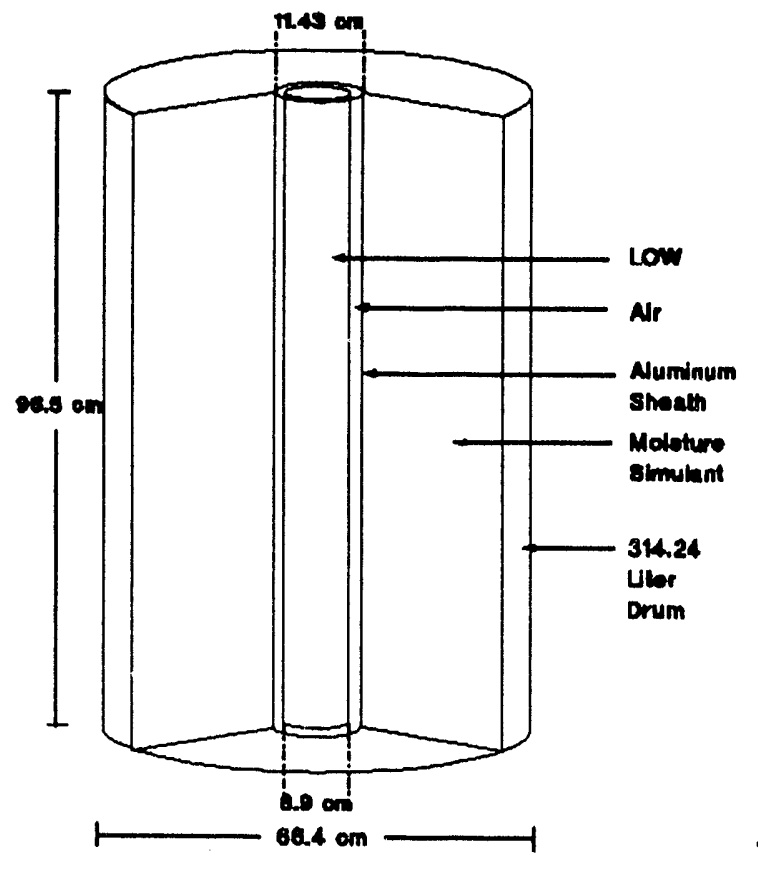

an unknown bound water content was probably not measured by the technique. The vendor of the sorbent claims that bound water usually comprises about 2 to 4 weight percent of the sorbent. The amount of bound, and therefore the total moisture in the sorbent, was one of the larger unknowns in the conditions associated with the limited calibration measurements.

The probe was usually deployed in the standards through a section of fiberglass LOW. Because only one LOW section was available for use, the standards (except for the water barrel) were equipped with a $1 / 8$-in. thick aluminum casing into which the LOW could be inserted and removed. Four standards were used: one containing water only; and three containing sorbent with about 8,17 , or 32 weight percent water. The unbound moisture content of the three sorbent-containing standards was measured using the moisture analyzer on more than six samples from each standard. The lowest moisture content standard was found to contain $5.66 \pm 0.31$ weight percent unbound water. The next standard was found to contain $14.79 \pm 0.22$ weight percent unbound water, and the highest moisture content standard contained $29.83 \pm 0.43$ weight percent unbound water. Data were also obtained for the probe placed in the water barrel without the LOW or aluminum casing surrounding the probe.

The MCNP model required an input spectrum for the AmBe neutron source. Such a chemical source does not produce a standard, defined neutron spectrum. Because no actual spectrum measurement is available for our source, a spectrum obtained from the literature 
was used initially in our model (Kluge and Weise 1982). Figure 3-3 shows the comparison of measured data with MCNP-calculated results for the neutron probe immersed in water for several source-to-detector spacings. The reported uncertainty of the measured results are indicative of the statistical error. The dashed line represents the MCNP results obtained using the source spectrum from the literature, and the solid line represents the MCNP results obtained after adjusting the input spectrum to better agree with the measured data.

Figure 3-4 shows the literature source spectrum and the adjusted source spectrum used to obtain better agreement. This source spectrum adjustment may not be a unique way to achieve the demonstrated agreement between model predictions and actual measurements. The adjustment of the modeled source spectrum was the most reasonable method of adjusting the model. The source strength was also varied to obtain a best fit to the measured data. Although the source is known to contain $1.5 \mathrm{Ci}$ of ${ }^{241} \mathrm{Am}$, the neutron yield from a chemical source is not defined. Based upon comparisons of data and MCNP calculations, the source was found to have a neutron yield of about $2.0 * 10^{6}$ neutrons $/$ second $/ \mathrm{Ci}$ of ${ }^{241} \mathrm{Am}$. Other unknowns associated with the current $\mathrm{AmBe}$ neutron source include source geometry, inner encapsulation material and geometry, the ratio of americium atoms to beryllium atoms, and the exact location of the source within its encapsulation. Our model assumes that the source contains 1 americium atom for every 13 beryllium atoms, a typical ratio for this type of source. The source is modeled at the center as defined by the outer encapsulation geometry. The source volume is modeled as cylindrical, with height equal to twice the diameter. The inner encapsulation is assumed to be tantalum. The effects of these unknowns upon model predictions were investigated by parametric modeling studies. The location of the source within its encapsulation seems to be the only parameter that strongly effects the predicted tool response.

A sample of the fiberglass LOW section used in the standards was submitted to the WHC Process Chemistry Laboratory for elemental analysis. The results of that analysis showed that 8.1 weight percent $\mathrm{B}_{2} \mathrm{O}_{3}$ was present in the LOW glass, and that approximately 29 weight percent of the LOW composite was glass. The LOW manufacturer estimated that the LOW glass contains 8 to 9 weight percent $\mathrm{B}_{2} \mathrm{O}_{3}$ and that the glass comprises about 65 weight percent of the composite. A more accurate determination of the glass content of the composite could be obtained (using a different laboratory technique) from another LOW sample. To make a model determination of the glass content of the LOW, the calibration data obtained for the LOW surrounded by water were modeled while adjusting the weight percent glass in the composite. Figure 3-5 shows a comparison of the measured data and MCNP calculations of the detector response for the neutron probe in a LOW surrounded by water for different assumed weight percent glass in the LOW. The best agreement was obtained between the measured data and the calculations for about 32 weight percent glass in the composite. This is in reasonable agreement with the laboratory estimate.

Figure 3-6 shows a comparison of the data obtained for several source-to-detector spacings in the three moisture concentration standards with corresponding MCNP calculations. The three striped bands (labeled according to unbound moisture content) represent the uncertainty introduced in the MCNP calculations by uncertainties in the bound moisture concentrations 
WHC-EP-0695

Figure 3-3. Comparison of Measured Values and MCNP Modeled Detector Responses with the Probe Immersed in Water.

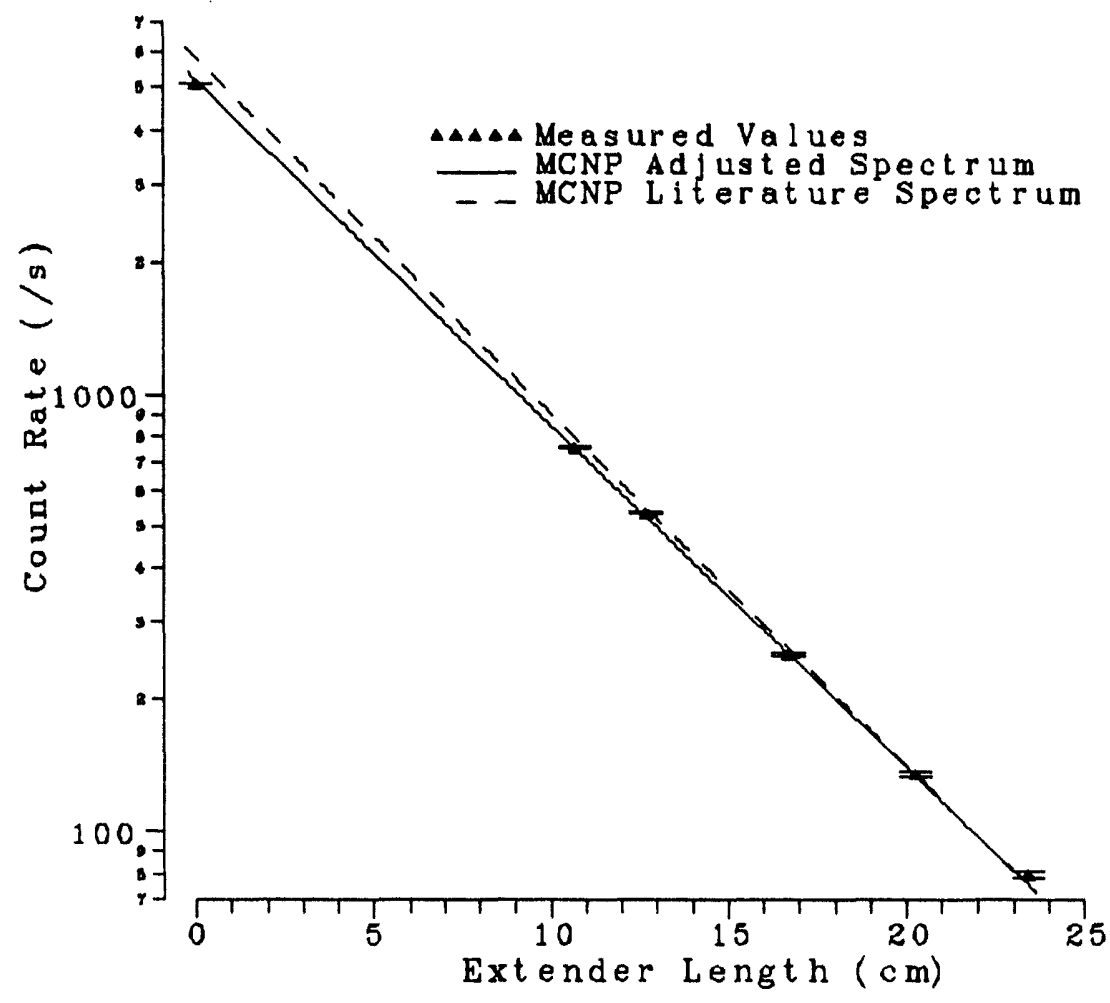

Figure 3-4. Comparison of a Literature Neutron Source Spectrum with the MCNP Modeled Spectrum Used to Obtain Best Agreement with Measured Data.

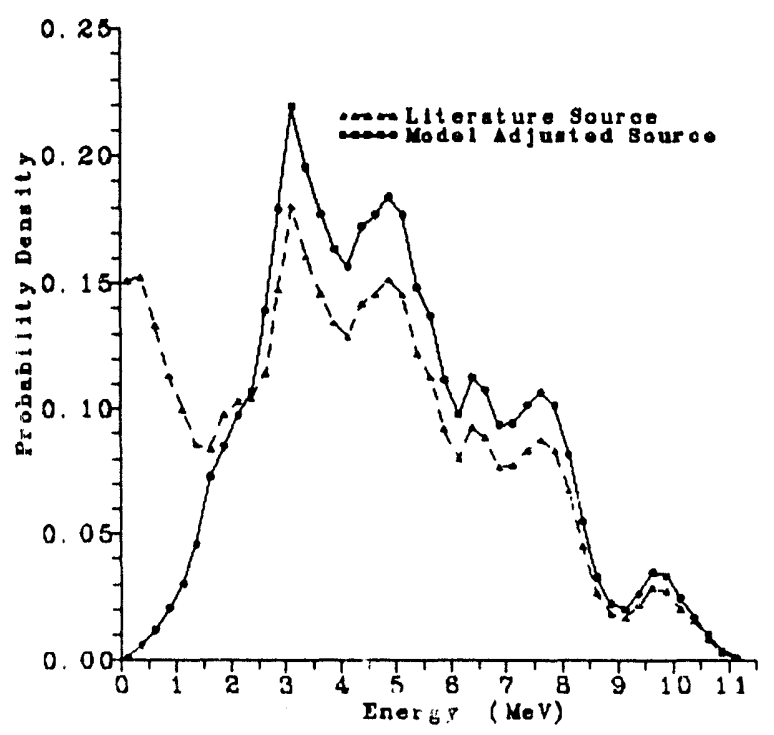


Figure 3-5. Comparison of Measured Values and MCNP Modeled Detector Responses with the Probe Inside a LOW Immersed in Water.

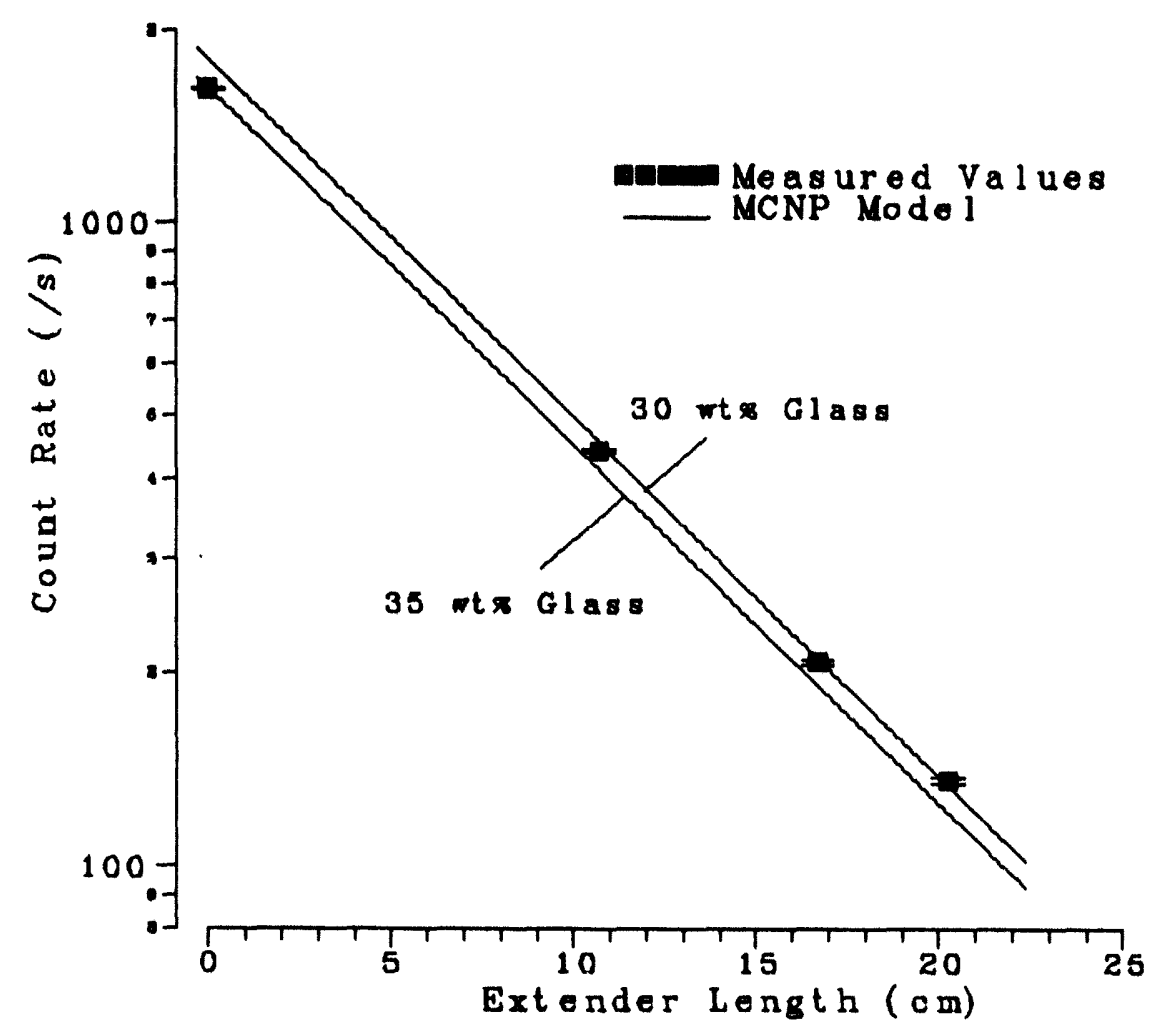

Figure 3-6. Comparison of Measured Values and MCNP Modeled Detector Responses with the Probe Deployed in Moisture Standards.

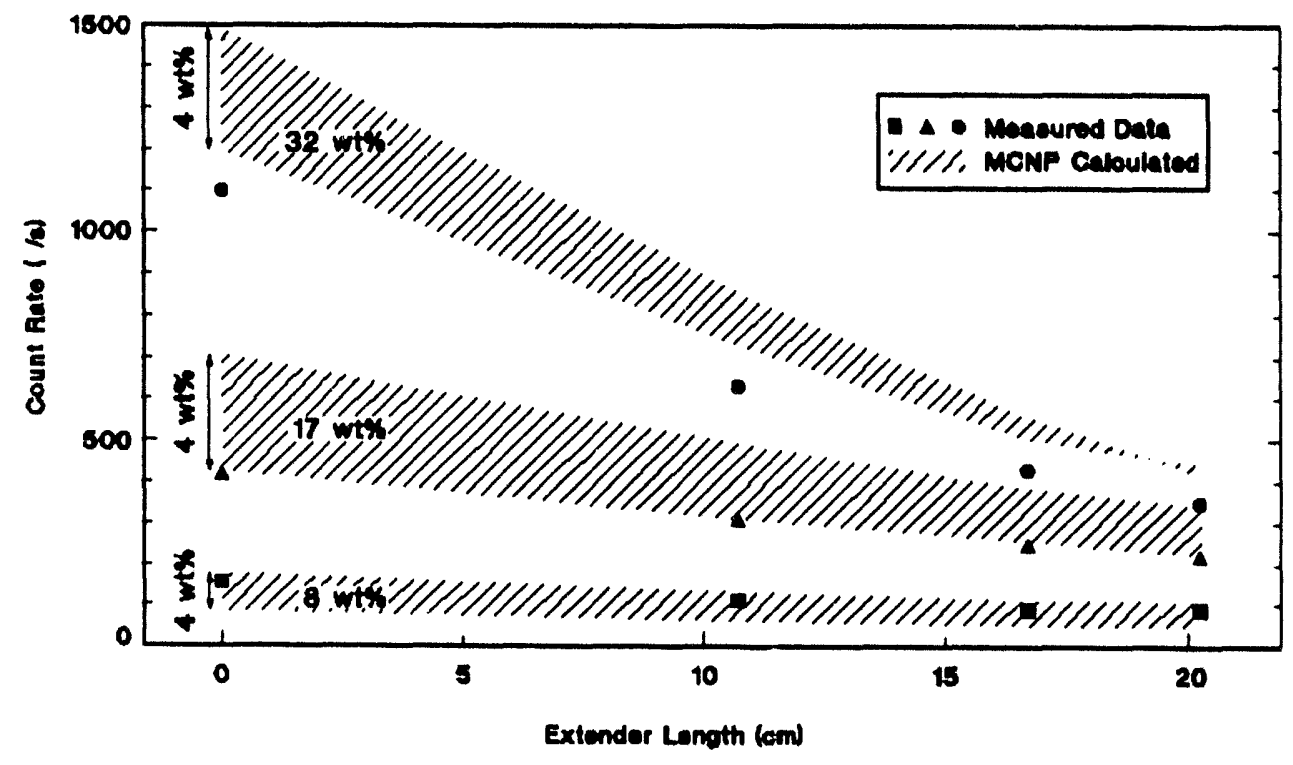


and in the densities of the three prepared sorbents. Because the moisture standard drums are not representative of infinite media at these low moisture concentrations and low densities, the detector response for long extender lengths increases with increasing moisture content. For these non-infinite media, it was necessary to model the moisture standard drums on either side of the given measured drum and the concrete floor below the drums. Data points are the measured values, and striped regions are the calculated uncertainty bounds based upon moisture content.

The most probable explanation for the disagreement in Figure 3-6 is that the sorbent, a natural sedimentary opal clay, contains trace amounts of strong neutron absorbers such as chlorine, lithium, or boron. The current detector response is strongly affected by the presence of strong neutron absorbers. The striped bands plotted in Figure 3-7 represent the model predictions, revised from Figure 3-6, with 0.02 weight percent natural boron present in the sorbent. Predicted tool responses are in excellent agreement with the measured data for this postulated sorbent composition. The measured density of the sorbent $\left(0.64 \mathrm{~g} / \mathrm{cm}^{3}\right)$ is not within the range specified by the vendor $\left(0.55\right.$ to $\left.0.58 \mathrm{~g} / \mathrm{cm}^{3}\right)$. This may be indicative of differences between the typical chemical composition supplied by the vendor and the true composition. To more accurately benchmark the model, a better defined material with a tightly controlled hydrogen content, density, and neutron absorber content may be required.

The moisture standard material composition contains a postulated 0.02 weight percent natural boron component. Data. points are the measured values, and striped regions are the calculated uncertainty bounds based upon moisture content.

Figure 3-8 compares measured values and modeled detector responses for two source-todetector separations. The model results were obtained using a vendor-supplied sorbent chemical composition and the best estimate of the total, bound and unbound, moisture content of each standard.

Figure 3-9 shows the results of processing the data shown in Figure 3-8 by dividing both measured and calculated responses for no extender cases by responses obtained with the $20.25 \mathrm{~cm}$ extender $(38.6 \mathrm{~cm}$ source-to-detector spacing). It is important to notice that this data processing leads to the cancellation of some types of systematic errors and to better moisture resolution over a wider range of moisture contents. Although the individual detector responses (see Figure 3-8) are not precisely predicted by the MCNP model (probably because of trace neutron absorbers), the ratios of these responses agree quite well. For an infinite medium, further improvement in the moisture resolution is expected. 
Figure 3-7. Comparison of Measured Values and MCNP Modeled Detector Responses with the Probe Deployed in Moisture Standards.

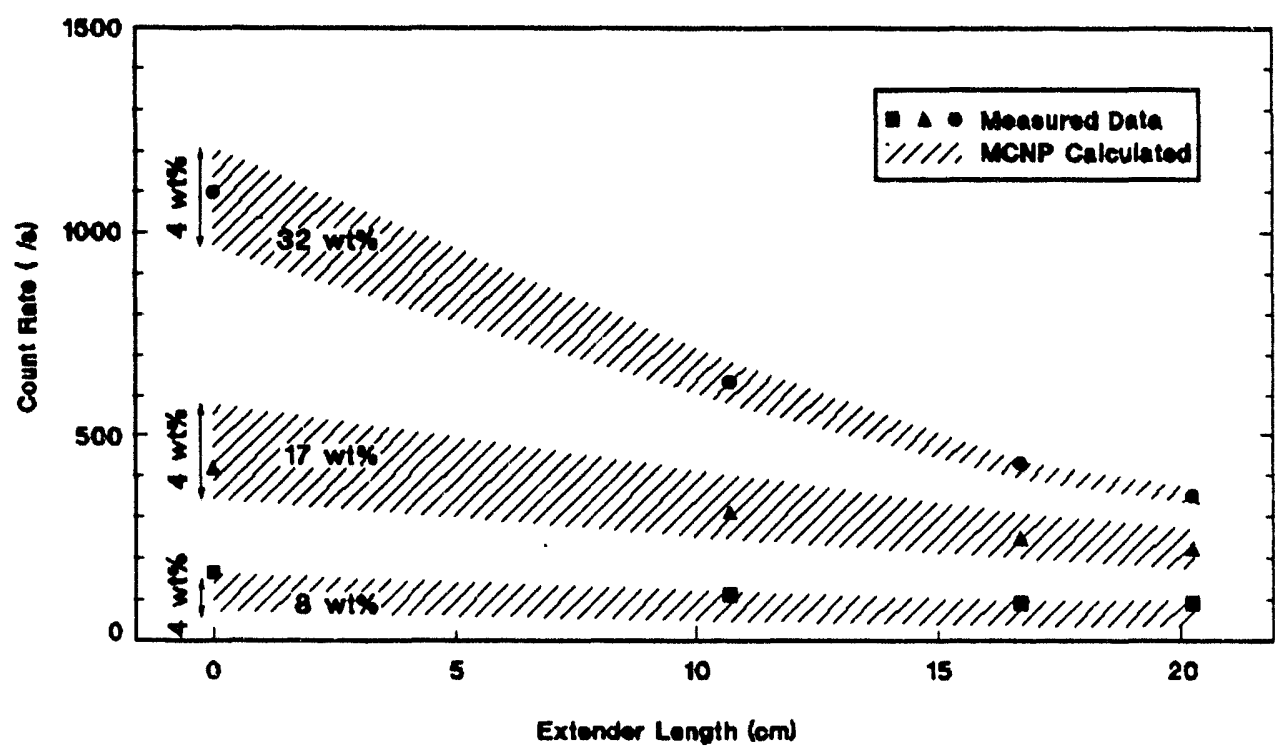

Figure 3-8. Comparison of Measured Values and MCNP Modeled Detector Responses for Two Source-to-Detector Separations.

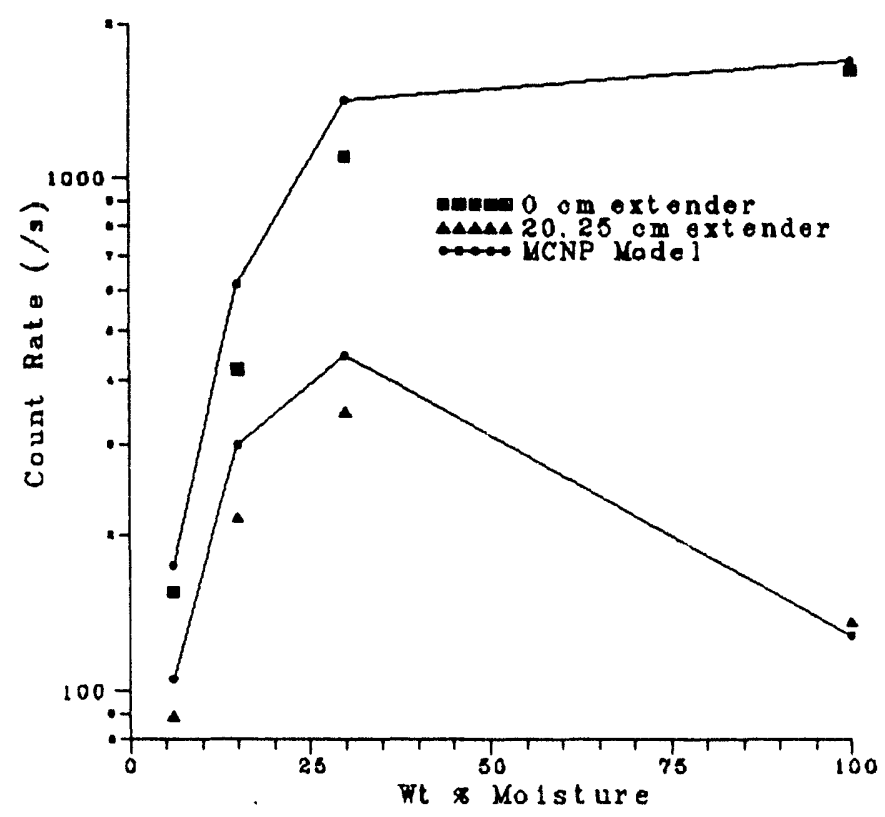


Figure 3-9. Comparison of Measured and MCNP Modeled Response Ratios for Two Source-to-Detector Separations (probe response with no extender divided by that with a $20.25 \mathrm{~cm}$ extender).

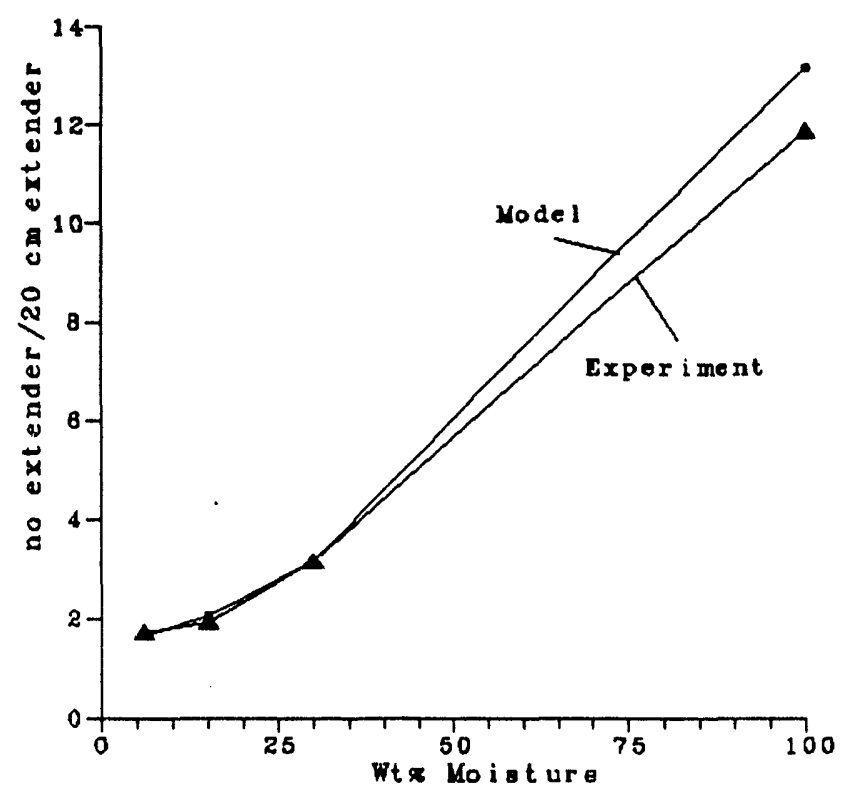


WHC-EP-0695

This page intentionally left blank. 


\subsection{INTERPRETATION OF TANK SCANS}

Scans have been obtained in three ferrocyanide Watch List tanks using the current in-tank neutron probe for two source-to-detector spacings. These scans were obtained in tanks 241-BY-107, 241-BY-110, and 241-BY-111. Each of these tanks has been interim stabilized and therefore contains little or no pumpable liquid. In order to relate the axial counting rates observed in these scans to an axial moisture concentration profile, WHC modeled the probe response to best estimate tank 241-BY-104 saltcake and sludge for different water concentrations. The density used in the model was $1.6 \mathrm{~g} / \mathrm{cm}^{3}$ for the sludge and $1.7 \mathrm{~g} / \mathrm{cm}^{3}$ for the saltcake. To perform initial calculations, WHC used the calibration-adjusted MCNP model and assumed that the LOW material composition was identical to that measured in the laboratory. Initial model results for expected near-field (no extender) count rates in high moisture content sludge were about 30 percent belaw the average count ra.es observed in the sludge region of all three tanks. For the sludge region of all three tanks, average count rates observed in the scans for the near-field probe were between 2100 and 2500 counts per second. As shown in Figure 4-1, the experimentally observed count rate for the zero extender length (near-field) probe placed within the LOW surrounded by 100 percent water is only $1616 \pm 3.7$ counts per second. Using the same boron content LOW as in the laboratory sample, there was no reasonable material that could be modeled around the LOW to predict the high count rates observed in the scans. Passive neutron scans have been obtained in several tanks without a neutron source attached to the detector; the background counting rates due to gamma rays or spontaneous fission neutrons are usually less than 1 count per second.

Figure 4-1. MCNP Predicted Near-Field Detector Response to Sludge with 10 Weight Percent Borosilicate LOW Content.

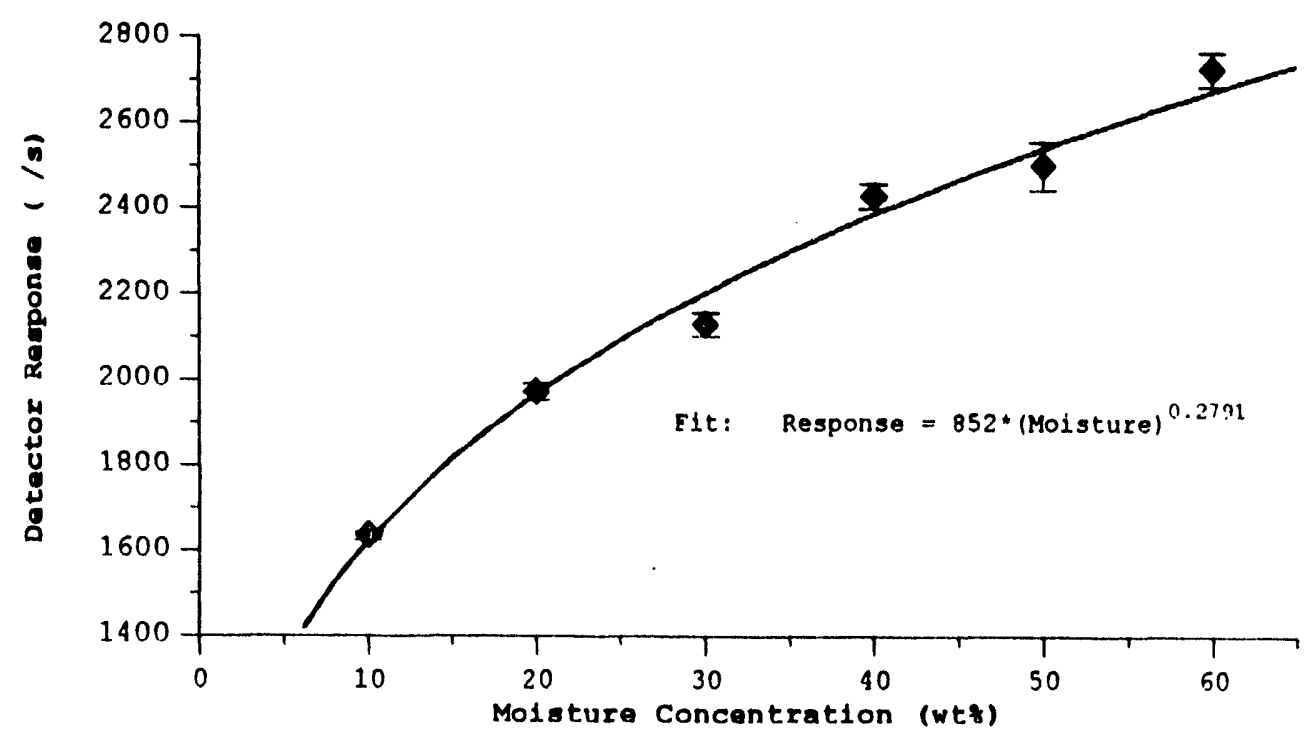


The most plausible solution explaining the scan results is to assume that the boron content of the tank LOWs was less than that of the laboratory LOW section. To confirm this, WHC took advantage of the scan data obtained in the riser/soil region of the scan. The LOW is inserted into a 4-inch schedule 40 steel pipe through the soil into tanks $241-\mathrm{BY}-110$ and 241-BY-111 and through a 12-inch schedule 40 steel pipe into tank 241-BY-107. The probe was modeled within the LOW in each of these risers for the two source-to-detector spacings. The soil surrounding the risers was modeled using material information about the 241- $\mathrm{T}$ Tank Farm backfill composition (Routson et al. 1979) and assuming 5 weight percent moisture content and a bulk density of $1.85 \mathrm{~g} / \mathrm{cm}^{3}$. This soil is comprised primarily of diorite, basalt, and granite, each of which is primarily composed of silica oxide. The borosilicate fiber content of the LOW was varied, beginning with the amount that gave best agreement between modeled and measured results in the calibration. Table 4-1 measured count rates for the two riser sizes for both the near- (no extender) and far-field $(20.25 \mathrm{~cm}$ extender) measurements. The model-predicted count rates for both the near- and far-field results average within 2.7 percent of the average observed values when the LOW is modeled with 10 weight percent borosilicate fiber in the LOW. The reported modeling results each have a statistical uncertainty of less than 3 percent.

Table 4-1. Modeled Predicted Probe Count Rates Compared with Measured Count Rates in the Riser/Soil Region.

\begin{tabular}{|l|c|c|c|c|c|}
\hline \multirow{2}{*}{} & \multirow{2}{*}{$\begin{array}{c}\text { Model Fiber } \\
\text { Content (wt\%) }\end{array}$} & \multicolumn{2}{|c|}{ 4-inch Riser } & \multicolumn{2}{c|}{ 12-inch Riser } \\
\cline { 3 - 6 } & & Model (/s) & Measured (/s) & Model (/s) & Measured (/s) \\
\hline near-field & 10 & 1454 & 1992 & 792 & 744 \\
\hline & 32 & 999 & & 552 & \\
\hline far-field & 10 & 523 & 539 & 442 & 429 \\
\hline & 32 & 361 & & 291 & \\
\hline
\end{tabular}

The model-predicted count rates are given for two different LOW borosilicate fiber contents.

\subsection{INTERPRETATION OF SLUDGE REGION DETECTOR RESPONSES}

With data supporting the assertion that the LOW boron content in the scanned tanks is lower than that found in the laboratory sample, WHC proceeded to model typical ferrocyanide sludge containing different moisture concentrations. Actual sludge composition and density are not well known. Figure 4-2 shows the calculated detector response of the near-field (18.3 $\mathrm{cm}$ source-to-detector spacing) probe configuration to a 10 weight percent borosilicate fiber LOW surrounded by tank $241-\mathrm{BY}-104$ sludge (density $=1.6 \mathrm{~g} / \mathrm{cm}^{3}$ ) of different moisture concentrations. A power law fit has been applied to the calculated data and seems to be representative of the data over the range of interest. The error bar displayed for each calculated value is representative of the stochastic uncertainty associated with that value. The 
model assumes that the sludge is in direct contact with the outer LOW surface. The calculated far-field ( $38.6 \mathrm{~cm}$ source-to-detector spacing) detector response to various moisture content sludge is shown in Figure 4-3. A power law fit is applied to the calculated data. If the detector system were fully calibrated and the modeled waste composition was representative of the tank material, it should be possible to predict moisture concentrations based upon the near- or far-field detector response alone.

Figure 4-2. MCNP Predicted Far-Field Detector Response to Sludge with 10 Weight Percent Borosilicate LOW Content.

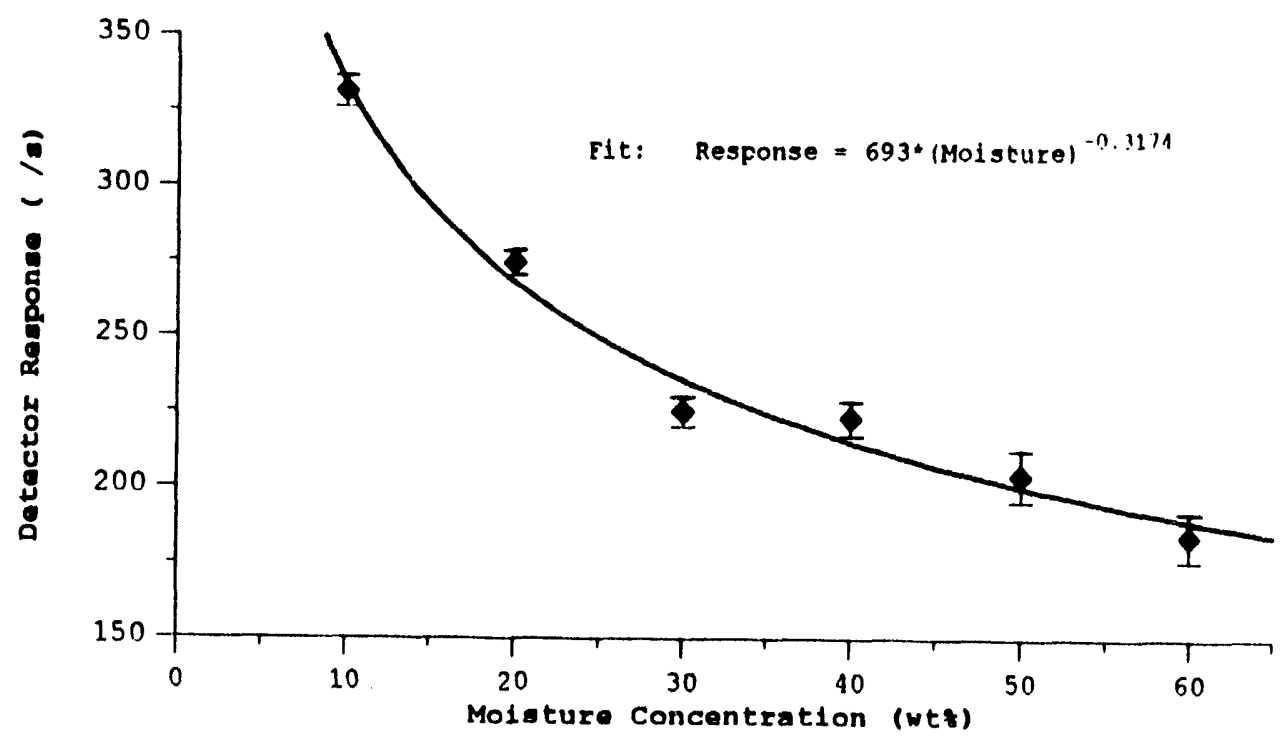

Figure 4-3. Calculated Near- to Far-Field Ratio Sludge Moisture Calibration Curve.

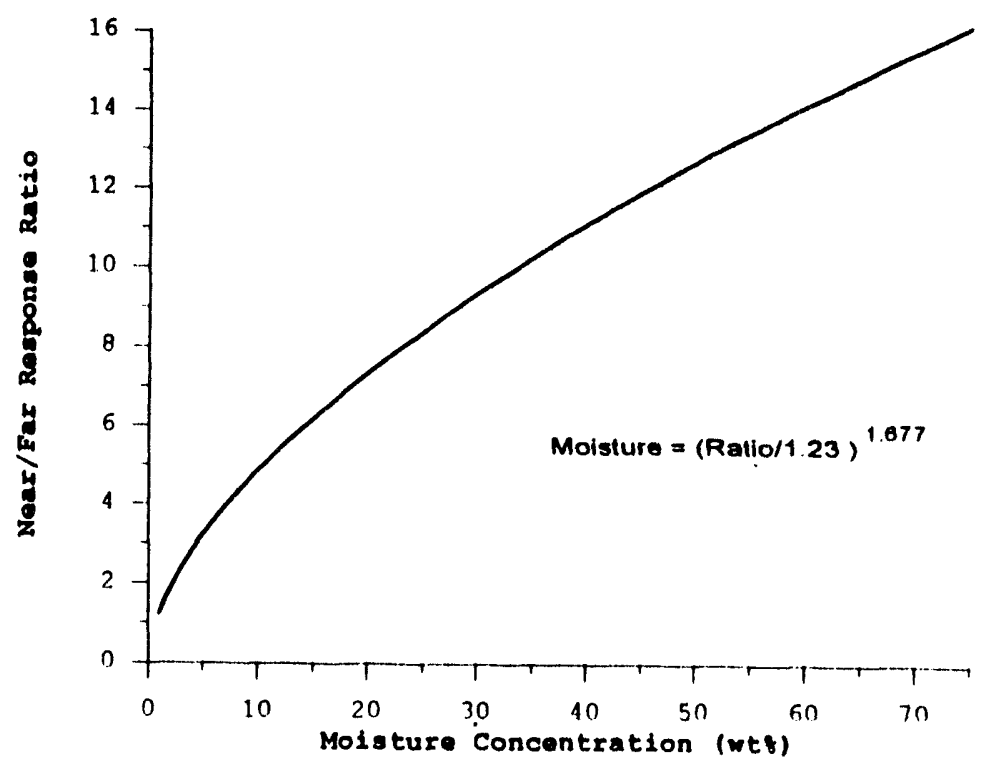


Further improvement in the moisture prediction is usually gained by using the ratio of these two responses. This ratio will often reduce or cancel some systematic uncertainties in the measurement as well as correct for some near-borehole effects. The ratio of the responses will usually give a better estimate of the moisture content of the surrounding material than a single detector measurement. Figure 4-4 shows the calculated near-to far-field response ratio to sludge as a function of the moisture concentration. The curve shown in this figure provides a calculated calibration function that can be applied to determine the sludge moisture content as a function of the response ratio of the near- and far-field detectors. The curve was developed for homogeneous surrounding tank materials and cannot be applied without adjustment to material interfaces, such as the interface between saltcake and sludge.

This calculated calibration curve has not been confirmed with experimental measurements in known moisture waste simulant and must therefore be considered theoretical and preliminary. Based on available core sampling data, a relatively high value for the sludge density $\left(1.6 \mathrm{~g} / \mathrm{cm}^{3}\right)$ was chosen for modeling. Using a larger value for the density in the model will cause the model to predict a conservative or lower than best estimate of moisture concentration in the sludge.

Figure 4-4 shows actual neutron probe scans of tank 241-BY-107. The result of dividing the near-field response by the far-field response is superimposed on actual scans. All scan values are originally measured with respect to the vertical position of the source. These scans have been shifted so that the response is plotted versus the depth in the tank at which the probe is most sensitive to the surrounding media. Modeling has shown that this position, rather than the source position, is about halfway between the source and the detector. MCNP modeling was performed to determine this most sensitive vertical position for each source-to-detector spacing, and the result was used to shift each scan by the appropriate distance. Five regions of the complete scan have been identified: riser/soil, riser/dome (concrete), tank airspace, saltcake, and sludge. Detector responses in the riser regions of the scan may not be directly compared with responses in the waste because of the air gap, steel riser casing, and the different material compositions and densities. The general trends observed in each of these regions are consistent with model expectations. In general, an increase in the near- to far-field response ratio is indicative of an increased hydrogen concentration in the surrounding material. The ratio is relatively low in the riser/soil region and increases in the riser/dome region. This is consistent with the expectation of low moisture in the soil and increased bulk density and hydrated water in the concrete tank dome. A more pronounced result is observed in the waste. The response ratio is about three times larger in the sludge region than in the saltcake region.

Scan data are collected for 1 second at 1/10-foot intervals. The uncertainty in the unprocessed data is due to the Poisson counting uncertainties in individual data values. Because a calibration has not yet been performed for typical ferrocyanide sludge and because the current probe uses thermal detectors, the actual total uncertainty for the present measurement cannot be accurately estimated at this time. The calculated detector response ration is higher than in the saltcake and remains relatively constant throughout much of this region, indicating constant moisture concentration higher than that observed in the saltcake 
Figure 4-4. Tank 241-BY-107 Neutron Scans and Near- to-Far-Field Response Ratio.

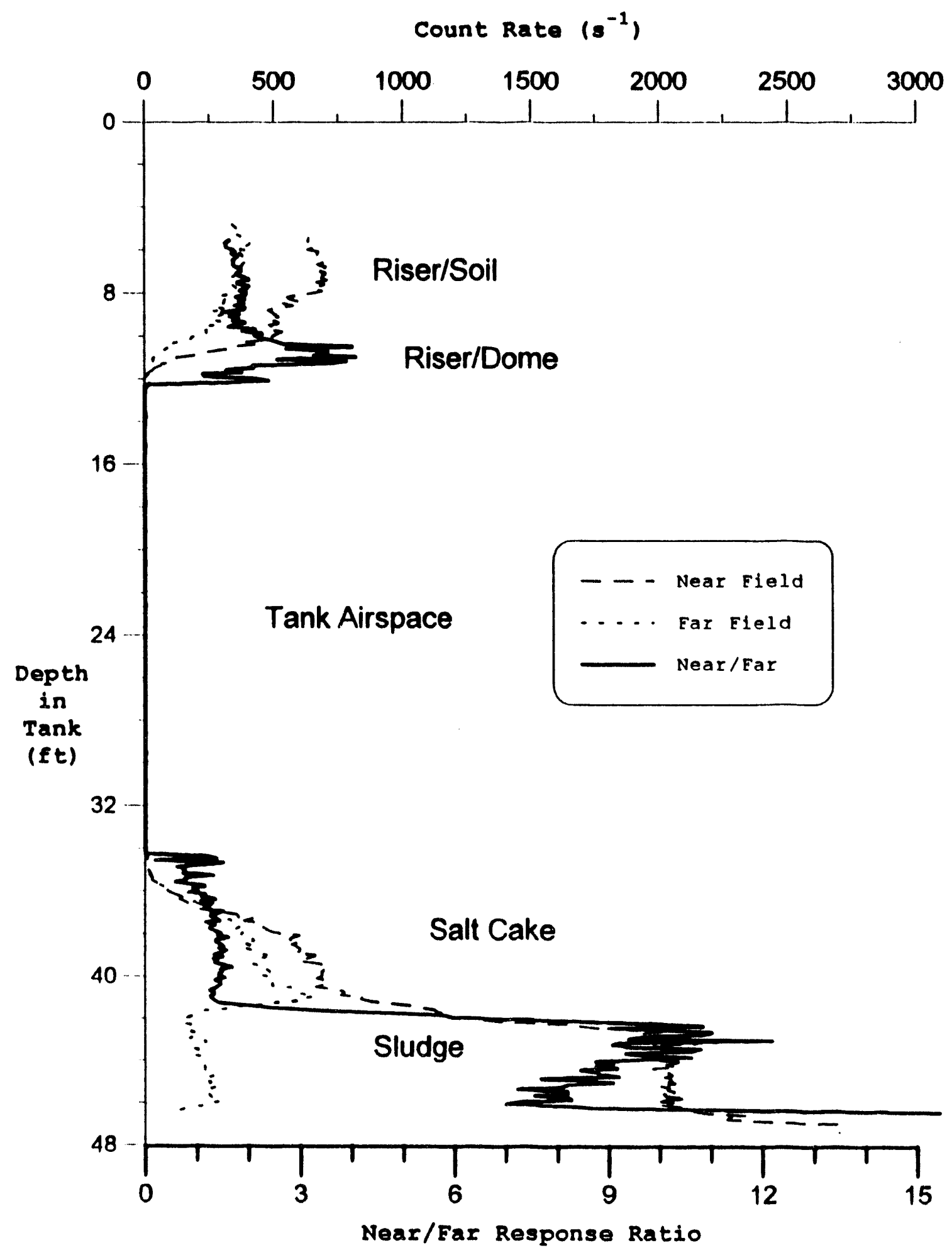


region. Relatively high values for the detector response ratio are observed for the bottom two data points acquired in the scans. The near-field response increases, and the far-field response decreases rapidly in this region of the tank. The LOW installation drawing (H-2-91924) specifies that LOWs are to be installed with a minimum 2-inch clearance between the bottom of the LOW and the tank liner. The observed effect may correspond to an actual significant increase in the moisture content of the sludge or may be produced by the proximity of the probe to the tank bottom. A similar feature is observed in the scans of tank 241-BY-111 but not in the scans obtained in tank 241-BY-110.

Figure 4-5 shows actual neutron probe scans of tank 241-BY-111. The result of dividing the near-field response by the far-field response is superimposed upon the actual scans. The detector response ratio plots for tanks 241-BY-111 and 241-BY-107 are very similar.

Figure 4-6 shows actual neutron probe scans of tank 241-BY-110. The result of dividing the near-field response by the far-field response is superimposed on the actual scans. No anomalous effect in the detector response ratio is observed in the scan data obtained near the bottom of this tank.

\subsection{INTERPRETATION OF THE SALTCAKE REGION DETECTOR RESPONSES}

The interpretation of the scan data obtained from the saltcake region of each tank is complicated because the LOW insertion through the hardened saltcake required that a water lance be used to create an opening. Figure 4-7 shows an actual in-tank photograph of the LOW inserted in the saltcake of tank 241-BY-107. The LOW is the green-colored fiberglass

pipe. Because the entrance hole for the LOW is larger than the LOW, an annular air gap exists around the LOW. Because the saltcake is somewhat solid, it does not appear to slump back in around the LOW, as is the postulated behavior for the sludge. If the saltcake had been more like a slurry at the time of LOW insertion, it might have filled in around the LOW. The annular air gap affects the detectors' responses. It should be possible to correct for such an air annulus using modeling in conjunction with experimental tests. Figure 4-5 shows the predicted responses of both near- and far-field detectors to different radius annular air holes between the LOW and low- to high-moisture saltcake (density $=1.7 \mathrm{~g} / \mathrm{cm}^{3}$ ). Because the far-field detector arrangement normally interrogates a larger volume of the surrounding material than the near-field probe, its response is less sensitive to near-borehole air gaps until the size of the air gap becomes comparable to the far-field source-to-detector spacing.

The LOW entrance hole into the saltcake is only visible in available in-tank photographs for tank 241-BY-107 (see Figure 4-7). Using this photograph, the diameter of the entrance hole was estimated by measuring its apparent size and comparing that with the apparent size of the LOW, whose outer radius is known to be $4.445 \mathrm{~cm}$. A best estimate of the radius of the saltcake entrance hole is $7.9 \mathrm{~cm}$ (measured from center of hole to edge of saltcake). If this size hole wan maintained throughout the saltcake, modeling results predict that the count rates for the near-field probe should reach about 1700 counts per second for one saltcake 
Figure 4-5. Tank 241-BY-111 Neutron Scans and Near- to Far-Field Response Ratio.

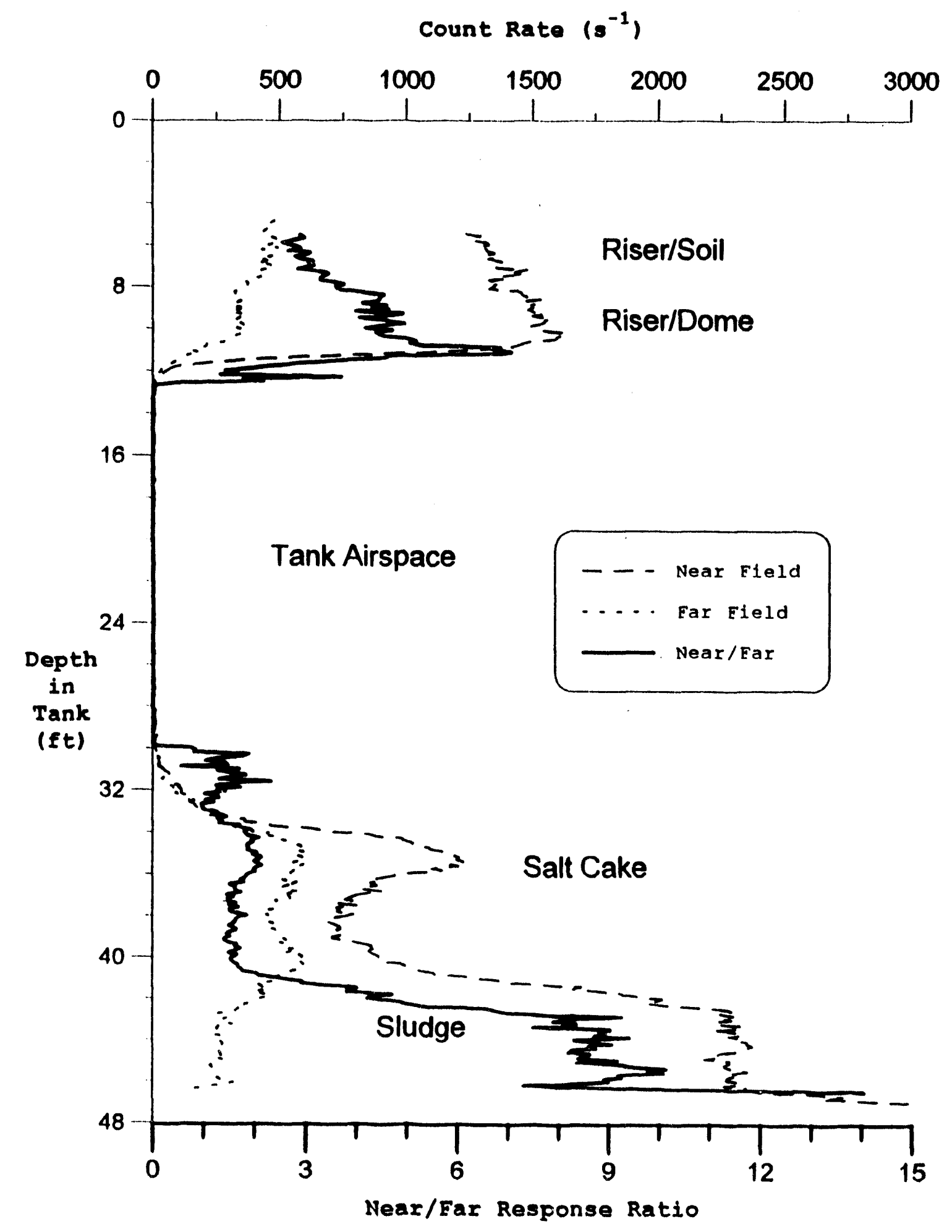


Figure 4-6. Tank 241-BY-110 Neutron Scans and Near- to Far-Field Response Ratio.

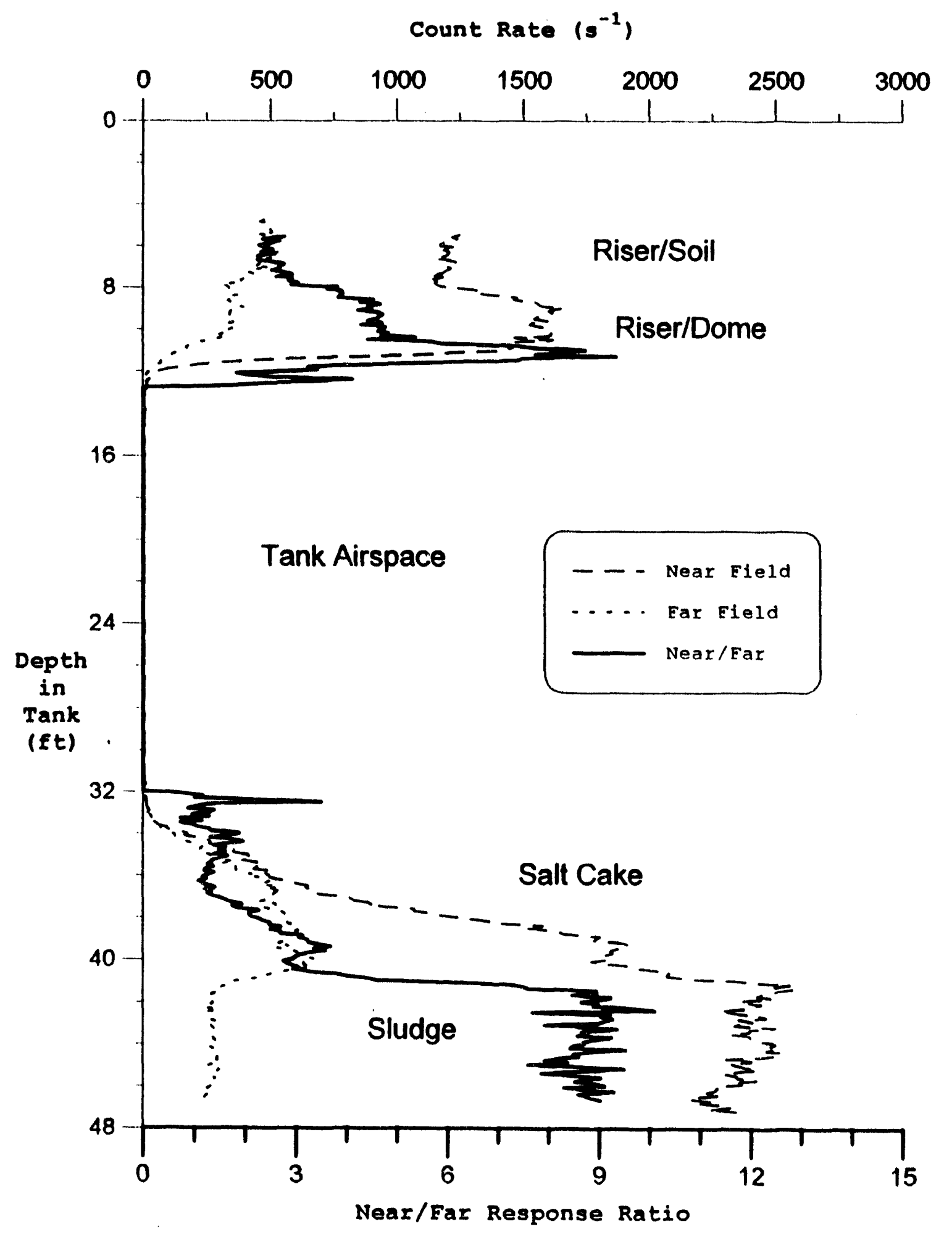


Figure 4-7. In-Tank Photograph of LOW and its Entrance into the Saltcake of Tank 241-BY-107.

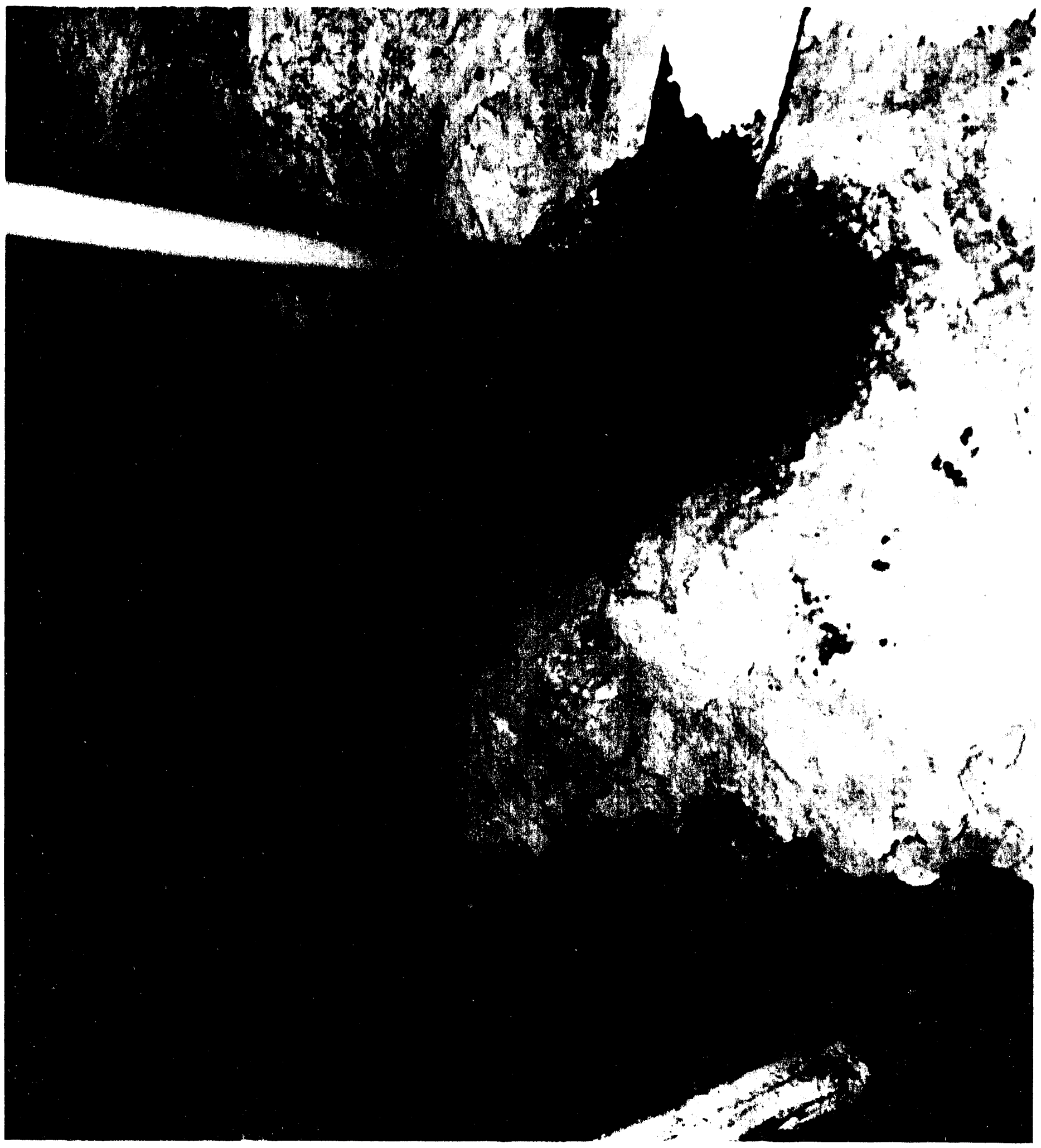


This page intentionally left blank. 
region and about 1500 counts per second in a region with less moisture. The observed nearfield count rate in the saltcake region of tank 241-BY-107 only rises to about 700 counts per second, while the far-field count rate averages about 500 counts per second in the same region.

The most plausible interpretation of these results is that, although the water lance appears to have produced a clean entrance hole in the saltcake, the annular air space around the LOW must increase to about 15 to $25 \mathrm{~cm}$ in radius below the saltcake surface. Figures 4-8 and 4-9 show that, for the LOW surrounded by a $20 \mathrm{~cm}$ radius air annulus followed by average moisture saltcake, the predicted count rates in tank saltcake for both the near- and far-field probe are in good agreement with those observed in the scans obtained in tank 241-BY-107. Without the information gained from both the near- and far-field detectors, this analysis would be difficult to substantiate. Accurate measurements of the saltcake moisture concentration from within an LOW surrounded by an air gap are more difficult than without the gap. If the size of the air gap is unknown, a simple ratio of the near- and far-field detector response is not adequate information on which to base a moisture estimate. Absolute count rate information must be combined with this ratio to determine the approximate air gap size and surrounding moisture concentration simultaneously. Experiments must be performed to confirm the model predictions for different air gaps between the LOW and saltcake of different moisture concentrations.

The scan data obtained in the saltcake region of tank 241-BY-111 exhibits more pronounced evidence of changing air anriulus size between the LOW and saltcake. The near-field count rate initially rises to a plateau of about 1180 per second, while the far-field reaches about 570 counts per second after both probes have completely entered the saltcake. These individual count rates are both consistent with those predicted for about a $12 \mathrm{~cm}$-radius air annulus surrounded by average moisture saltcake. At a depth of about $11.58 \mathrm{~m}$ in the tank, the near-field count rate has fallen to about 750 per second and the far-field count rate has dropped to about 430 per second. These absolute count rates and their ratio are consistent with those predicted for about a $17 \mathrm{~cm}$-radius annular air hole surrounded by average moisture saltcake. The saltcake scan data are consistent with what would be expected for saltcake containing a relatively constant moisture concentration of about average moisture throughout its vertical profile, but with a relatively small LOW insertion air hole that increases in radius about $.60 \mathrm{~cm}$ below the surface of the saltcake. Because of possible air hole variations, it is likely that the saltcake portion of the scan for each tank will require an individual analysis and interpretation that may not lend itself to the automated use of a single calibration curve. 
Figure 4-8. Calculated Near- and Far-Field Responses to Annular Air Holes Between LOW and Saltcake (Low and High Moisture).

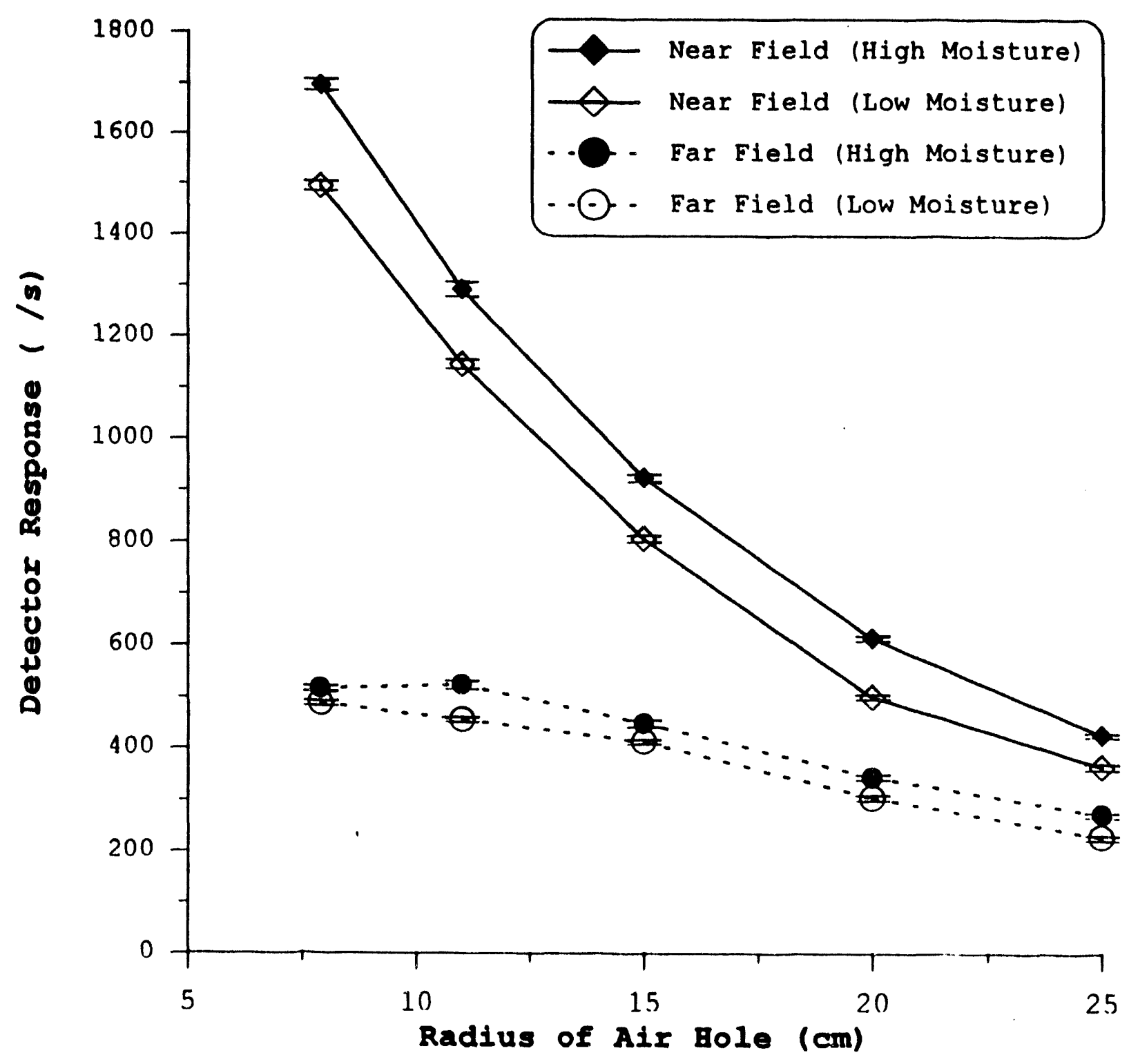


Figure 4-9. Comparison of Calculated Responses of an Epithermal Detector to Different Moisture Concentration Sludge for Two LOW Borosilicate Concentrations.

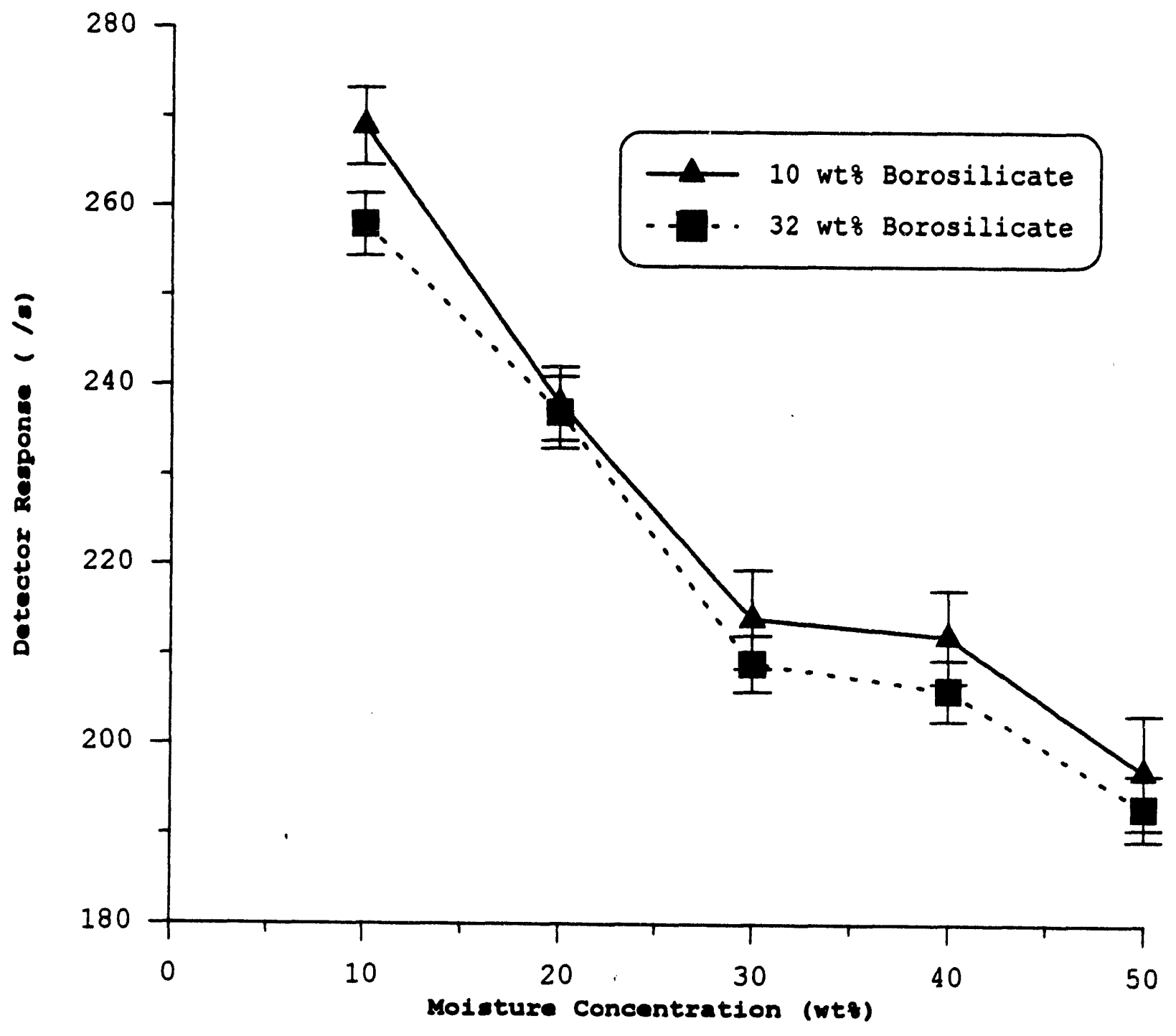


This page intentionally left blank. 


\subsection{DESIGN RECOMMENDATIONS FOR AN IMPROVED MOISTURE MEASUREMENT NEUTRON PROBE}

Several improvements over the current interstitial liquid level neutron probe may be easily included in a new design. A new design should include multiple detectors at appropriate spacings from the source. The most useful information probably would be obtained using three detectors, two in the near-field response region and one in the far-field response region. The far-field and one of the near-field detectors should be used to detect epithermal neutrons in order to eliminate the effects of the LOW' boron content and the possible presence of strong neutron absorbers in the waste matrix. An epithermal system should measure the moderating properties rather than the neutron absorption properties of the surrounding media. Figure 4-9 shows the calculated response of the current near-field detector wrapped with a 4-mm-thick polyethylene inner sleeve and a 2.5 -mm-thick outer gadolinium sleeve to sludge of different moisture concentrations with two widely different LOW borosilicate fiber contents. The outer gadolinium sleeve absorbs thermal neutrons allowing higher energy neutrons to enter the inner polyethylene sleeve where their energy is reduced by collision. These neutrons then enter the active detector region with an energy that is more efficiently detected. The predicted response of this epithermal neutron detector nearly eliminates the effects caused by the borosilicate content of the LOW, while maintaining a reasonably high count rate and good sensitivity to moisture variations. This same device should enable more accurately determination interstitial liquid levels in Hanford Site tanks. The current probe, when configured in its shortest source to detector spacing ( $18.3 \mathrm{~cm}$ center-to-center) is not a true near-field detector. A near-field detector is more effective when it is placed closer to the source and shortened in length. Another desirable improvement would be the ability to control the scan rate of the system so that more data could be acquired over scan intervals of interest, thereby improving the counting statistics. More ideal measurements, requiring less complicated interpretation, could be made from within a well casing inserted through the saltcake and sludge without using a water lance. For example, an insertion method using a penetrometer would minimally disturb the waste immediately surrounding the casing. 
WHC-EP-0695

This page intentionally left blank. 


\subsection{CONTINUING DEVELOPMENT AND INVESTIGATION}

To complete the development and final deployment of a neutron moisture measurement device for routine surveillance purposes, several tasks must be performed. Tank waste moisture simulants must be procured and used to obtain final experimental measurements and calibrations. With these simulants, WHC will want to investigate the response of the prototype probe to moisture concentrations, geometrical air- or liquid-filled regions around the LOW, and vertical material interfaces. These simulants will be representative of actual ferrocyanide waste (without radioisotopes). The simulants must only be the equivalent of ferrocyanide wastes in terms of their elemental composition and density, because neutron interactions are essentially unaffected by the chemical structure binding elements other than hydrogen.

To deploy a prototype neutron probe in the field, changes must be implemented in the drywell surveillance vans hardware. The vans currently perform scans using gamma and neutron probes in cased, air-filled wells at the Hanford Site. The vans are equipped with a draw-works that physically controls and measures the height of the probe in the well using a single conductor, armor-jacketed cable. The probe's analog signal is transmitted along the cable to the van's data acquisition system, and DC power is supplied to the probe transformer using the same cable. To make the vans compatible with the currently proposed neutron probe design, additional data acquisition electronics will be required. Additional data acquisition electronics will be needed to receive and process the signals from the added detectors. The draw-works of the drywell van should also be modified to allow for variable and slower scan rates. Currently the probes must be scanned at speeds of 0.03 or $0.015 \mathrm{~m}$ per second. The ability to stop the scan and collect data for longer times at certain intervals and the ability to perform continuous scans at rates down to $0.0009 \mathrm{~m}$ per second are desirable. Longer counting times provide measurements with less statistical uncertainty, while allowing a weaker source to be used for safety considerations.

LOWs have not yet been installed in all ferrocyanide tanks at the Hanford Site. The design and material composition of additional LOWs must be determined to allow current and proposed in-tank LOW monitoring tools to function effectively.

To obtain more accurate interpretations of scans, both experimental measurements and computer modeling will be used to determine the responses of the detectors to possible airor liquid-filled regions immediately surrounding the LOW. The possibility of using a pulsed neutron system to identify and correct for such anomalies will be investigated with computer modeling. 
WHC-EP-0695

This page intentionally left blank. 


\subsection{CONCLUSIONS}

The ability of a simple, active neutron probe to respond in a predictable manner to changes in surrounding moisture concentration has been demonstrated. Measurements have been obtained, using a slightly modified in-tank neutron probe, both in experimental moisture standards and in actual tank waste. The results from these measurements compare favorably with predictions made by computer modeling of the device's response to these various conditions and materials. Using theoretical model predictions and best estimate tank material compositions and densities, estimates of tank material moisture concentrations may be derived from scan data. Valuable information has been obtained regarding tank conditions under which an improved device must be able to measure moisture. With more complete calibrations and better knowledge of materials, modeling has shown that an improved neutron device should be capable of measuring moisture concentrations with increased accuracy and with decreased uncertainty in Hanford Site waste tanks. 


\section{WHC-EP-0695}

This page intentionally left blank. 


\subsection{REFERENCES}

Crowe, R. D. and D. L. Heer, 1992, Potential of Estimating Moisture Content in Waste Tanks Using the Existing Neutron Probe, WHC-SD-WM-RPT-037 Rev. 0, Westinghouse Hanford Company, Richland, Washington.

Goncalves, I. F., J. Salgado, and F. Carvalho, 1992, "Calibration of a Neutron Moisture Gauge by Monte-Carlo Simulation," Nuclear Geophysics, Vol. 6, No. 3, pp. 371-381.

Hearst, J. R. and R. C. Carlson, 1993, A Comparison of the Moisture Gauge and the Neutron Log in Air-filled Holes, Lawrence Livermore National Laboratory Preprint, UCRL-JC-112454 (Rev. 1), Livermore, California.

Hearst, J. R. and P. H. Nelson, 1985, Well Logging for Physical Properties, McGraw-Hill Book Co., New York, New York.

IAEA (International Atomic Energy Agency), 1970, "Neutron Moisture Gauges," Technical Report Series 112, Vienna.

Kluge, H. and K. Weise, 1982, "The Neutron Energy Spectrum of a ${ }^{241} \operatorname{AmBe}(\alpha, n)$ Source and Resulting Mean Fluence to Dose Equivalent Conversion Factors," Radiation Protection Dosimetry, Vol. 2, No. 2, pp. 85-93.

LANL, 1986, MCNP - A General Purpose Monte Carlo Code for Neutron Photon Transport, Version 3A, LA-7396-M, Rev. 2, (J. E. Briesmeister, Ed.) Los Alamos National Laboratory, Los Alamos, New Mexico. (Documentation for Version 4.2 has been released but not in a formal document.)

Locke, J. and J. Butler, 1993, Characterization of Rock Formations for the Improved Calibration of Nuclear Logging Tools, AEA Technology, Winfrith, UK.

McKague, H. L., J. Hearst, R. Ward, and N. Burkhard, 1992, "Nuclear Magnetic Resonance Determination of the Nonpore Water Content of Zeolitic Tuffs and its Application to Correction of Epithermal-neutron-derived Water Content," Nuclear Geophysics, Vol. 6, pp. 359-366.

Mills, W. R., D. Stromswold, and L. Allen, 1991, "Advances in Nuclear Oil Well Logging," Nuclear Geophysics, Vol. 5, No. 3, pp. 209-227.

Routson, R. C., W. H. Price, D. J. Brown, and K. R. Fecht, 1979, High Level Waste Leakage From the 241-T-106 Tank at Hanford, RHO-ST-14, Rockwell Hanford Operations, Richland, Washington. 
Soran, P. D., D. C. Mckeon, and T. E. Booth, 1990, "Calculation of Monte Carlo Importance Functions for Use in Nuclear-Well Logging Calculations," IEEE Transactions on Nuclear Science, Vol. 37, No. 2, pp. 936-942. 


\section{DISTRIBUTION}

\section{Number of copies}

\section{OFFSITE}

12

U.S. Department of Energy

EM-35, Trevion II

Washington, D.C. 20585

John C. Tseng

1

U.S. Department of Energy

Savannah River Operations Office

P.O. Box A

Aiken, South Carolina 29808

Thomas C. Temple

1

Charles S. Abrams

1987 Virginia

Idaho Falls, ID 83404

1

David O. Campbell

102 Windham Road

Oak Ridge, TN 37830

1

Fred N. Carlson

6965 North 5th West

Idaho Falls, ID 83401

1

Donald T. Oakley

409 12th Street SW, Suite 310

Washington, DC 20024-2188

1

Arlin K. Postma

3640 Ballard Road

Dallis, Oregon 97338

1

William R. Prindle

1556 Crestline Drive

Santa Barbara, CA 93105 


\section{DISTRIBUTION (continued)}

Number of copies

OEFSITE

1

Alfred Schneider

5005 Hidden Branches Drive

Dunwoody, GA 30338

1

Air Products \& Chemicals. Inc. 7201 Hamilton Blvd

Allentown, PA 18195-1501

George E. Schmauch

1

Battelle Columbus Laboratories

505 King Avenue

Columbus, OH 43201-2693

James A. Gieseke

1

Brookhaven National Laboratory

Upton, NY 11973

Kamal K. Bandyopadhyay

1

Desien Science, Inc.

163 Witherow Road

Sewickley, PA 15143

Gary Powers

1

Fauske and Associates. Inc. 16W070 W. 83rd St.

Burr Ridge, IL 60521

Hans K. Fauske

1

Florida State University

Department of Chemistry B-164

Tallahassee, FL 32306

Greg R. Choppin 


\section{DISTRIBUTION (continued)}

\section{Number of copies}

\section{OEESITE}

1

Harvard University

295 Upland Avenue

Newton Highlands, MA 02161

Melvin W. First

1

Hazards Research Corporation

200 Valley Road, Suite 301

Mt. Arlington, NJ 07856

Chester Grelecki

1

4

Billy C. Hudson

Los Alamos National Laboratory

P.O. Box 1663

Los Alamos, NM 87545

Steve F. Agnew

Steve W. Eisenhawer

Thomas E. Larson

L. Harold Sullivan

MTT/Department of Nuclear Engineering

77 Massachusetts Ave.

Room 24-102

Cambridge, MA 02139

Mujid S. Kazimi 


\section{DISTRIBUTION (continued)}

Number of copies

\section{OEFSITE}

1

Nuclear Consulting Services, Inc.

P.O. Box 29151

Columbus, OH 43229

J. Louis Kovach

Oak Ridge National Laboratory

1

Emory D. Collins

P.O. Box 2008

7930, MS-6385

Oak Ridge, TN 37831-6385

1

Charles W. Forsberg

P.O. Box 2008

MS-6495

Oak Ridge, TN 37831-6495

1

Thomas S. Kress

P.O. Box 2009

9108, MS-8088

Oak Ridge, TN 37831-8088

1

Rice University

5211 Paisley

Houston, TX 77096

Andrew S. Veletsos

1

Sandia National Laboratory

P.O. Box 5800

Albuquerque, NM 87185

Scott E. Slezak 


\section{DISTRIBUTION (continued)}

\section{Number of copies}

\section{OFFSITE}

Science Applications International Corporation 12850 Middlebrook Road

Trevion I, Suite 300

Germantown, MD 20874

Ray S. Daniels (3)

1

State of Washington

Department of Ecology

P. O. Box 47600

Olympia, WA $98504-7600$

Michael T. Gordon

1

University of South Carolina

Department of Electrical and Computer Engineering

Swearingen Engineering Center

Columbia, SC 29208

Joseph S. Byrd

1

University of Washington

Center for Process Analytical Chemistry

Chemistry Department BG-10

Seattle, WA 98195

Bruce R. Kowalski

1

Vanderbilt University

P.O. Box 1596, Station B

Nashville, TN 37235

Frank L. Parker 


\section{DISTRIBUTION (continued)}

Number of copies

ONSITE

U.S. Department of Energy,

Richland Field Office

R. F. Christensen (4)

R3-72

R. E. Gerton

R3-72

A. G. Krasopoulos

A4-81

Public Reading Room

$\mathrm{H} 2-53$

RL Docket File (2)

H5-36

8

Pacific Northwest Laboratory

R. T. Allemann

K7-15

S. A. Bryan

P7-25

B. M. Johnson

K1-78

M. A. Lilga

P8-38

R. D. Scheele

P7-25

G. F. Schiefelbein

P8-38

D. M. Strachan

K2-38

Hanford Technical Library

P8-55

52

Westinghouse Hanford Company

H. Babad

R2-78

G. A. Barnes

H5-09

J. B. Billetdeaux

R2-08

D. C. Board

S1-57

G. L. Borsheim

R2-11

S. R. Moreno

B3-06

R. J. Cash (2)

R2-78

M. D. Crippen

L5-31

G. M. Christensen

H4-21

D. R. Dickinson

L5-31

G. T. Dukelow

R2-78

J. C. Fulton

R2-31

K. A. Gasper

R2-08

J. M. Grigsby

H4-62

H. D. Harmon

R2-52

D. A. Healey

T4-07

J. M. Held

R3-09 


\section{DISTRIBUTION (continued)}

Number of copies

ONSITE

Westinghouse Hanford Company (continued)

M. N. Islam

R3-08

D. W. Jeppson

L5-31

D. R. Johnson

R2-08

N. W. Kirch

R2-11

C. A. Kuhlman

B3-30

M. Kummerer

H4-62

J. D. McCormack

L5-31

J. M. McLaren

H0-34

J. E. Meacham

R2-78

N. J. Milliken

H4-62

T. L. Moore, Sr

H5-09

A. F. Noonan

R2-12

R. S. Yopielarczyk

R1-30

R. W. Reed

R1-51

F. R. Reich

L5-63

C. P. Schroeder

L7-06

B. C. Simpson

R2-12

J. P. Summerhays

R2-85

H. Toffer

HO-38

W. T. Watson (5)

H0-38

W. D. Winkelman

L5-55

D. D. Wodrich

H0-30

D. D. Wodrich

R2-85

W. F. Zuroff

R2-14

Central Files

L8-04

EDMC

H6-08

Information Release Administration (3)

R1-05

TFIC

R1-20 
This page intentionally left blank. 
$r$
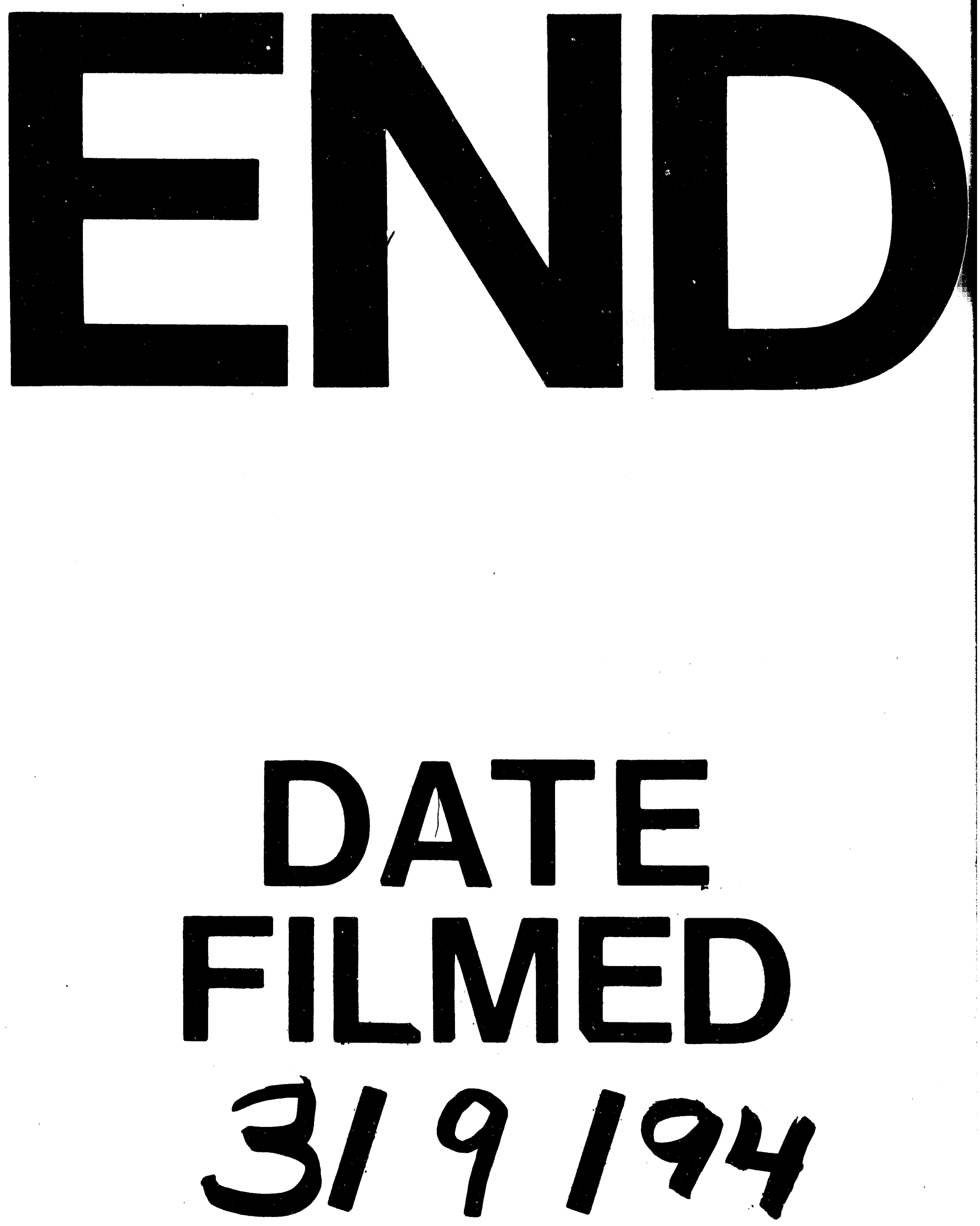

1 
